\title{
Overview and Strategy Analysis of Technology-Based Nonpharmacological Interventions for In-Hospital Delirium Prevention and Reduction: Systematic Scoping Review
}

Chan Mi Kim ${ }^{1}$, MSc; Esther M van der Heide ${ }^{2}$, PhD; Thomas J L van Rompay ${ }^{3}$, PhD; Gijsbertus J Verkerke ${ }^{4,5}$, Prof Dr; Geke D S Ludden ${ }^{1}$, Prof Dr

\footnotetext{
${ }^{1}$ Department of Design, Production, and Management, Faculty of Engineering Technology, University of Twente, Enschede, Netherlands

${ }^{2}$ Patient Care and Monitoring Department, Philips Research, Eindhoven, Netherlands

${ }^{3}$ Department of Communication Science, Faculty of Behavioral, Management, and Social Sciences, University of Twente, Enschede, Netherlands

${ }^{4}$ Department of Biomechanical Engineering, Faculty of Engineering Technology, University of Twente, Enschede, Netherlands

${ }^{5}$ Department of Rehabilitation Medicine, University of Groningen, University Medical Center Groningen, Groningen, Netherlands
}

\section{Corresponding Author:}

Chan Mi Kim, MSc

Department of Design, Production, and Management

Faculty of Engineering Technology

University of Twente

De Horst (Building 20)

Enschede

Netherlands

Phone: 31534898450

Email: c.m.kim@utwente.nl

\section{Abstract}

Background: Delirium prevention is crucial, especially in critically ill patients. Nonpharmacological multicomponent interventions for preventing delirium are increasingly recommended and technology-based interventions have been developed to support them. Despite the increasing number and diversity in technology-based interventions, there has been no systematic effort to create an overview of these interventions for in-hospital delirium prevention and reduction.

Objective: This systematic scoping review was carried out to answer the following questions: (1) what are the technologies currently used in nonpharmacological technology-based interventions for preventing and reducing delirium? and (2) what are the strategies underlying these currently used technologies?

Methods: A systematic search was conducted in Scopus and Embase between 2015 and 2020. A selection was made in line with the Preferred Reporting Items for Systematic reviews and Meta-Analyses extension for Scoping Reviews (PRISMA-ScR). Studies were eligible if they contained any type of technology-based interventions and assessed delirium-/risk factor-related outcome measures in a hospital setting. Data extraction and quality assessment were performed using a predesigned data form.

Results: A total of 31 studies were included and analyzed focusing on the types of technology and the strategies used in the interventions. Our review revealed 8 different technology types and 14 strategies that were categorized into the following 7 pathways: (1) restore circadian rhythm, (2) activate the body, (3) activate the mind, (4) induce relaxation, (5) provide a sense of security, (6) provide a sense of control, and (7) provide a sense of being connected. For all technology types, significant positive effects were found on either or both direct and indirect delirium outcomes. Several similarities were found across effective interventions: using a multicomponent approach or including components comforting the psychological needs of patients (eg, familiarity, distraction, soothing elements).

Conclusions: Technology-based interventions have a high potential when multidimensional needs of patients (eg, physical, cognitive, emotional) are incorporated. The 7 pathways pinpoint starting points for building more effective technology-based interventions. Opportunities were discussed for transforming the intensive care unit into a healing environment as a powerful tool to prevent delirium.

Trial Registration: PROSPERO International Prospective Register of Systematic Reviews CRD42020175874; https://www.crd.york.ac.uk/prospero/display_record.php?RecordID=175874 
(J Med Internet Res 2021;23(8):e26079) doi: 10.2196/26079

\section{KEYWORDS}

intensive care unit; delirium; delirium prevention; delirium reduction; delirium treatment; technology; technology-based intervention; strategy; nonpharmacological; systematic scoping review

\section{Introduction}

\section{Background}

Delirium is an acute brain dysfunction with a disturbance in attention, awareness, and cognition [1], which is common, especially in critically ill patients. It occurs in about $40 \%$ of patients in the intensive care unit (ICU) [2], and in case of ventilated patients, the proportion goes up to about $65 \%-80 \%$ $[2,3]$. Nonetheless, delirium can be often underestimated due to differences in the severity of illness in populations and underrecognition of delirium [4,5]. Delirium is frequently associated with a significant increase in the ICU length of stay [6], risk of long-term cognitive impairments [7], and 6-month mortality rates after leaving the ICU [8]. At the organizational level, delirium is associated with an increase in the cost of ICU care [9], ICU readmission [10], and mental stress of ICU nurses who take care of patients with delirium [11]. At the societal level, delirium costs up to $\$ 152$ billion per year in health care in the United States [12]. Prevention of delirium may be the most effective way to avoid these negative outcomes. In case of in-hospital patients, at least $30 \%-40 \%$ of delirium cases are preventable by reducing the risk factors of delirium $[13,14]$. There are 2 types of interventions used for preventing delirium: pharmacological and nonpharmacological interventions (eg, reorientation).

Nonpharmacological multicomponent interventions are recommended over pharmacological interventions as a safe and promising way of preventing delirium [15]. Nonpharmacological multicomponent interventions aim at reducing delirium risk factors that are modifiable by, for instance, promoting better sleep, early mobilization, and cognitive training/stimulation [15]. In order to support the implementation of nonpharmacological interventions, several methods [16,17] have been introduced. As an example, the ABCDEF bundle provides practical ways to provide optimal care of ICU patients [16]. Despite the benefits of using these methods [18], there are still barriers, as the way in which nonpharmacological interventions are applied is often highly dependent on the medical staff. Technology-based interventions might help to overcome these barriers. In this review, "technology" is defined as equipment that is used or developed based on scientific knowledge for practical purposes. Ironically, while the ICU room has been one of the most technology-intensive places in hospitals, when it comes to delirium prevention, the use of technology-based interventions in the ICU room often remains limited to, for example, the use of earplugs [19].

With recent developments in technology, there is large potential for the diversity of technology-based interventions. Examples include a modified ICU room design providing, among others, a personalized light therapy system and noise reduction to support cognitive stimulation and a normal sleep-wake cycle of patients [20]. Another example is an interactive app using a conversational agent, which provides patients social interactions and medical advice [21]. The app enables personalized care for patients without frequent physical visits of bedside nurses. These examples showcase some of the possibilities that recent developments in technology can bring. However, understanding how to optimize technology-based interventions is limited, and therefore, it is worthwhile to further and more systematically study the topic.

\section{Prior Work}

Recently, several (systematic) reviews have been performed to provide overviews and to highlight the potential of existing nonpharmacological interventions for preventing delirium [18,22-28]. However, none of the existing reviews focused exclusively on technology-based interventions for preventing delirium. Moreover, none of the previous reviews [25-27] provided information necessary for improving the design and development of new technology-based interventions. For instance, a vision outlining what is needed to build a better care environment for patients in the context of intensive care and clear guidance for technology-supported improvements are lacking.

\section{Goal of This Study}

To close this gap, this paper will provide a comprehensive review of technology-based interventions used for preventing and reducing in-hospital delirium. To our knowledge, this is the first systematic effort to provide such an overview. Taking a bottom-up approach, we will first investigate what types of technologies are used in current nonpharmacological interventions and how these interventions contribute to delirium prevention and reduction in hospitalized patients. Second, we will identify underlying strategies of technologies applied in the technology-based interventions. Finally, following our analysis, we will discuss the limitations of the current technology use and the opportunities for further research and development of technology-based interventions aimed at delirium prevention in the ICU and for other hospitalized patients. This systematic scoping review was conducted to answer the following questions: (1) what are the technologies currently used in nonpharmacological technology-based interventions for preventing and reducing in-hospital delirium? and (2) what are the strategies underlying these currently used technologies? This review will provide insights into technologies that can be used for in-hospital delirium prevention and reduction and suggest directions for future design and development of innovative technology-based interventions. We propose that incorporating these insights will optimize the use of technologies and enhance the effectiveness of technology-based interventions. 


\section{Methods}

\section{Search Strategy}

This systematic scoping review was conducted complying with the Preferred Reporting Items for Systematic reviews and Meta-Analyses extension for Scoping Reviews (PRISMA-ScR) guidelines [29]. The study protocol was registered on the international prospective register of systematic reviews (PROSPERO, CRD42020175874). The search was conducted from the Scopus and Embase databases for studies that are written in English and were published between January 1, 2015 and January 6, 2020 (Scopus)/January 13, 2020 (Embase). This time period was set to focus on the state-of-the-art technologies used following our scope for this review. The initial search was conducted with the terms delirium (deliri*) and technology (technolog*) but it did not result in a sufficient number of relevant studies. Samples of search terms were identified through previous studies and extended through the search of index terms, medical subject headings, and other technological terms used for other medical purposes. The following terms were used for the final search: (1) deliri*, (2) technolog*, (3) intelligen* OR automat* OR digital* OR computer OR computing OR robot*, (4) mobile OR app, (5) visual OR virtual OR VR OR video, (6) light* OR ambien* OR aroma* OR architect*, (7) sound* OR music* OR voice OR alarm, (8) cognitive training OR tracking OR game*, and (9) 1 AND 2 OR 3 OR 4 OR 5 OR 6 OR 7 OR 8 (see Multimedia Appendix 1 for the full search strategy). Additional studies were sought through communication with experts. Only studies that were peer reviewed and conducted with human subjects were included. The title-abstract screening and the full-text review were performed by 2 reviewers (CMK and $\mathrm{EMvdH}$ ) independently. Disagreements were discussed and reevaluated based on the main goal of the study. The reasons for excluding were recorded.

\section{Eligibility Criteria and Study Selection}

The studies were included based on the eligibility criteria (See Table 1).

Table 1. Eligibility criteria.

\begin{tabular}{|c|c|c|}
\hline Criterion & Inclusion criteria & Exclusion criteria \\
\hline Study type & $\begin{array}{l}\text { All types of original research published in peer-reviewed journals and } \\
\text { conferences }\end{array}$ & $\begin{array}{l}\text { Letters, comments, editorials, conference abstracts, or } \\
\text { any type of review }\end{array}$ \\
\hline Period & January 1, 2015 until January 6 (Scopus) and 13 (Embase) 2020 & $\begin{array}{l}\text { Before January 1, } 2015 \text { and after January } 6 \text { (Scopus), } \\
2020 \text { and January } 13 \text { (Embase), } 2020\end{array}$ \\
\hline Language & English & All other languages \\
\hline Population & In-hospital patients in all age groups & $\begin{array}{l}\text { Patients who are not in-hospital patients, healthy } \\
\text { participants }\end{array}$ \\
\hline Intervention & $\begin{array}{l}\text { Nonpharmacological interventions using any type of technology either } \\
\text { as a single intervention or as a part of multicomponent } \\
\text { intervention aiming at preventing or reducing delirium }\end{array}$ & $\begin{array}{l}\text { Pharmacological interventions, interventions only } \\
\text { focusing on detecting/screening delirium }\end{array}$ \\
\hline Comparator & Any comparator, including no comparator & $\mathrm{N} / \mathrm{A}^{\mathrm{a}}$ \\
\hline Outcome & $\begin{array}{l}\text { Delirium-related data (eg, occurrence, duration of delirium) or risk } \\
\text { factor-related data that indirectly influence delirium (eg, anxiety) }\end{array}$ & Neither delirium-related data nor risk factor-related data \\
\hline
\end{tabular}

${ }^{\mathrm{a}} \mathrm{N} / \mathrm{A}$ : not applicable.

The main goal of this review was to find papers dealing with the prevention and reduction of delirium in the ICU, but in order to not overlook the potential of a greater range of technology-based interventions, the search scope was not limited to the ICU department but included also other hospital departments (eg, pediatric ICU, geriatric ward). We also included delirium from all age groups: from acute pediatric delirium to geriatric delirium because they share a similar range of delirium symptoms [30]. Moreover, the risk factors and recommended interventions across delirium in these groups are more or less the same [31]. Although delirium consists of 3 subtypes, each of which have their own symptoms and courses [32], these subtypes were not applied in the eligibility criteria and the study selection, as most studies did not specify them. We included studies focusing on incident delirium as well as prevalent delirium in order to address the full scope of delirium interventions. As we intended to explore all existing

technology-based interventions supported by scientific evidence, we did not place any inclusion restrictions on the study design.

\section{Data Extraction and Quality Assessment}

Data extracted from the studies included the primary author, year of publication, country of origin, publisher, summary of intervention content, applied technology, intervention goal, study design, type and number of participants, outcome measure, intervention outcomes, key findings, and limitations of the study. The primary data extraction was performed by CMK using the predesigned data extraction form, and the extracted data were reviewed and confirmed by EMvdH. Disagreements were resolved by discussions between CMK and EMvdH, which included revisits of the relevant data by both authors. To distinguish differences in the strength of evidence in the studies, a quality assessment was performed by CMK using a predesigned assessment form (Multimedia Appendix 2) and reviewed and confirmed by EMvdH. Disagreements were resolved by follow-up discussions. However, none of the studies 
were excluded based on the quality assessment in our analysis as our goal in this review was to create an overview of the existing technology-based interventions.

\section{Data Analysis}

First, all technologies used in the technology-based interventions were looked into and clustered per technology type; a total of 8 categories was identified. Clustering was performed by CMK and reviewed and confirmed by EMvdH. Next, to summarize the strategies used in the technology-based interventions, goals and content summaries of each intervention were looked into, and 14 strategies were identified. These strategies were clustered and labelled based on the overarching theme: this led to the identification of 7 pathways to delirium prevention. An extraction of 14 elements from each intervention was carried

Figure 1. Flow diagram of study selection.

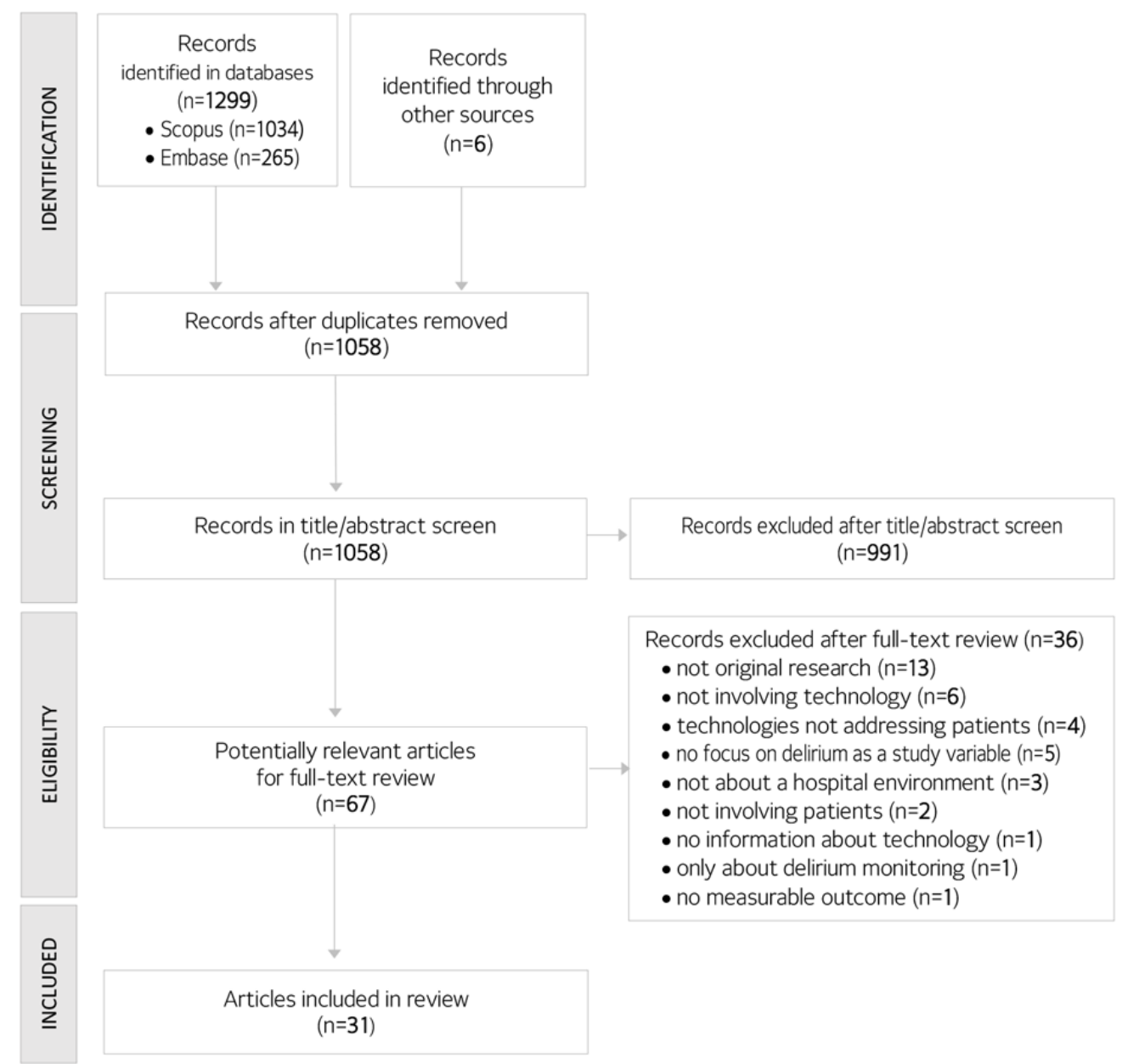

\section{Study Characteristics}

The characteristics of the 31 included studies are listed in Table 2. Most of the studies were conducted in the ICU $(15 / 31,48 \%)$ followed by hospital wards $(13 / 31,42 \%)$ and both ICU and hospital wards $(3 / 31,10 \%)$. The most common study population was adult patients $(23 / 31,74 \%)$. Seven studies were conducted out by CMK and clustering was performed independently by CMK and 2 other experienced researchers. After each session, the results and disagreements were discussed by CMK with the other experienced researchers, and then the synthesis was finalized by CMK.

\section{Results}

\section{Study Selection}

The process of literature screening and selection is presented in the flow diagram (Figure 1). After removing the duplicates, a total of 1058 studies were screened. Among these, 67 studies were examined based on the full text and 31 studies met inclusion for the review. with pediatric patients [33-39] and 1 study was conducted with both adult and pediatric patients [40]. Most studies were prospective studies $(28 / 31,90 \%)$, including randomized trials [33-49], pretest-posttest/experimental [19,21,24,50-52], organizational case study [53], observational cohort [54], and pilot studies [55-57]. There were 3 retrospective studies [58-60] (See Table 2 for further specifications). 
Table 2. Characteristics of the included studies classified into 8 different technology types.

\begin{tabular}{|c|c|c|c|c|}
\hline Technology type, study & Main goal of intervention & Study design & Patient type $^{\mathrm{a}}$ & Total number of patients (per group) \\
\hline \multicolumn{5}{|c|}{ Audio: music/voice message } \\
\hline $\begin{array}{l}\text { Damshens et al } \\
\text { [40] }\end{array}$ & To improve mental state ${ }^{\mathrm{b}}$ & $\begin{array}{l}\text { Randomized clinical } \\
\text { trial }\end{array}$ & $\begin{array}{l}\mathrm{ICU}^{\mathrm{c}} \text { (pediatric and } \\
\text { adult) }\end{array}$ & $80\left(I^{\mathrm{d}}: 40, \mathrm{C}^{\mathrm{e}}: 40\right)$ \\
\hline Lee et al [39] & To reduce stress and anxiety & $\begin{array}{l}\text { Randomized controlled } \\
\text { trial }\end{array}$ & ICU & 85 (I: 41, C: 44) \\
\hline Johnson et al [48] & To alter physiologic response & $\begin{array}{l}\text { Randomized controlled } \\
\text { trial }\end{array}$ & $\begin{array}{l}\text { ICU/trauma orthopedic } \\
\text { unit }\end{array}$ & 40 (I: 20, C: 20) \\
\hline Sharda et al [53] & $\begin{array}{l}\text { To mitigate postoperative pain } \\
\text { and anxiety }{ }^{b}\end{array}$ & $\begin{array}{l}\text { Organizational case } \\
\text { study }\end{array}$ & $\begin{array}{l}\text { Perioperative optimiza- } \\
\text { tion of senior health }\end{array}$ & 202 (I: 45, C: 157) \\
\hline Cheong et al [55] & $\begin{array}{l}\text { To enhance engagement and } \\
\text { mood and to improve agitated } \\
\text { behavior }^{\mathrm{b}}\end{array}$ & $\begin{array}{l}\text { Pilot study (for } \\
\text { randomized controlled } \\
\text { trial) }\end{array}$ & $\begin{array}{l}\text { Acute care unit (patients } \\
\text { with delirium, dementia, } \\
\text { or both) }\end{array}$ & 25 (I: 25, C: 25) \\
\hline Byun et al [33] & $\begin{array}{l}\text { To activate positive psycholog- } \\
\text { ical and behavioral responses } \\
\text { and to reduce anxiety }\end{array}$ & $\begin{array}{l}\text { Double-blind } \\
\text { randomized controlled } \\
\text { trial }\end{array}$ & $\operatorname{PACU}^{\mathrm{f}}$ (pediatric) & 66 (I1: 33, I2: 33) \\
\hline Munro et al [49] & $\begin{array}{l}\text { To support reorientation and to } \\
\text { comfort patients }{ }^{\mathrm{b}}\end{array}$ & $\begin{array}{l}\text { Three-group prospec- } \\
\text { tive randomized con- } \\
\text { trolled trial }\end{array}$ & $\mathrm{ICU}^{\mathrm{g}}$ & 30 (I1:10, I2:10, C: 10) \\
\hline \multicolumn{5}{|c|}{ Light: Dynamic light/natural light } \\
\hline Estrup et al [58] & To improve circadian rhythm ${ }^{\mathrm{b}}$ & $\begin{array}{l}\text { Retrospective cohort } \\
\text { study }\end{array}$ & ICU & 183 (I: 46, C: 137) \\
\hline Pustjens et al [60] & To improve circadian rhythm ${ }^{\mathrm{b}}$ & $\begin{array}{l}\text { Retrospective } \\
\text { observational cohort } \\
\text { study }\end{array}$ & Coronary care unit & 748 (I: 369, C: 379) \\
\hline Simons et al [41] & $\begin{array}{l}\text { To improve circadian rhythm } \\
\text { and sleep }{ }^{b}\end{array}$ & $\begin{array}{l}\text { Randomized controlled } \\
\text { single-center trial }\end{array}$ & ICU & 734 (I: 361, C: 373) \\
\hline $\begin{array}{l}\text { Potharajaroen et al } \\
\text { [42] }\end{array}$ & To improve sleep-wake cycle ${ }^{b}$ & $\begin{array}{l}\text { Single-blind random- } \\
\text { ized controlled study }\end{array}$ & ICU & 62 (I: 31, C: 31) \\
\hline Smonig et al [54] & $\begin{array}{l}\text { To reduce circadian rhythm } \\
\text { disruption }^{\text {b }}\end{array}$ & $\begin{array}{l}\text { Prospective single-cen- } \\
\text { ter observational study }\end{array}$ & ICU & 179 (I: 102, C: 77) \\
\hline \multicolumn{5}{|c|}{ Video/video game: information/distraction } \\
\hline Lee et al [50] & $\begin{array}{l}\text { To reduce preoperative } \\
\text { anxiety }^{\mathrm{b}}\end{array}$ & Quasi-experimental & ICU & 50 (I: 25, C: 25) \\
\hline Kim et al [34] & To reduce preoperative anxiety & $\begin{array}{l}\text { Prospective randomized } \\
\text { controlled trial }\end{array}$ & PACU (pediatric) & 104 (I1: 34, I2: 33, I3: 37) \\
\hline $\begin{array}{l}\text { Rodriguez et al } \\
\text { [35] }\end{array}$ & To reduce preoperative anxiety & $\begin{array}{l}\text { Prospective randomized } \\
\text { trial }\end{array}$ & PACU (pediatric) & 52 (I1: 25, I2: 27) \\
\hline $\begin{array}{l}\text { Waszynski et al } \\
\text { [43] }\end{array}$ & $\begin{array}{l}\text { To reduce agitation in patients } \\
\text { experiencing hyperactive or } \\
\text { mixed delirium }\end{array}$ & $\begin{array}{l}\text { Randomized controlled } \\
\text { trial }\end{array}$ & Hospitalized/ICU ${ }^{\mathrm{h}}$ & 111 (I1: 34, I2: 40, C: 37) \\
\hline Dwairej et al [36] & To reduce preoperative anxiety & $\begin{array}{l}\text { Randomized clinical } \\
\text { trial }\end{array}$ & $\begin{array}{l}\text { Day case surgery unit } \\
\text { (pediatric) }\end{array}$ & 128 (I: 64, C: 64) \\
\hline \multicolumn{5}{|c|}{ Virtual reality: information/distraction } \\
\hline Eijlers et al [37] & To reduce pain and anxiety ${ }^{b}$ & $\begin{array}{l}\text { Randomized controlled } \\
\text { single-blind trial }\end{array}$ & $\begin{array}{l}\text { Day case surgery unit } \\
\text { (pediatric) }\end{array}$ & 191 (I: 94, C: 97) \\
\hline Ryu et al [38] & To reduce preoperative anxiety & $\begin{array}{l}\text { Randomized controlled } \\
\text { trial }\end{array}$ & PACU (pediatric) & 86 (I: 41, C: 39) \\
\hline
\end{tabular}




\begin{tabular}{|c|c|c|c|c|}
\hline Technology type, study & Main goal of intervention & Study design & Patient type $^{\mathrm{a}}$ & Total number of patients (per group) \\
\hline Suvajdzic et al [57] & $\begin{array}{l}\text { To reduce clinical anxiety and } \\
\text { depression and to support sleep }\end{array}$ & Pilot test & ICU & 10 \\
\hline & and relaxation ${ }^{\mathrm{a}}$ & & & \\
\hline
\end{tabular}

\section{Sleep aids}

Demoule et al [44] To improve sleep quality

Van de Pol et al To improve sleep quality

[19]

\section{Communication aids}

Garry et al [56] To improve patient's

psychosocial status $^{\mathrm{b}}$

Bott et al [21]

To provide companionship, social support, and health information to decrease loneliness and depression ${ }^{\mathrm{b}}$

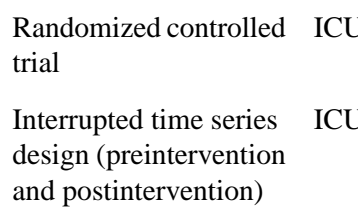

Interrupted time series design (preintervention and postintervention)

Pilot prospective trial

ICU/coronary care unit

Case control quasi-experimental pre-post (for randomized controlled trial)

\section{Others}

Lin et al [46]

Giraud et al [45] To make the children adapt to
the experience of visual disturbance

To support mental status, earlier physical mobilization, and multisensory feedback/integration

\section{Multiple components}

Arbabi et al [51]

To support reorientation, cognitive/physical activation, human interaction $^{\mathrm{b}}$

Tovar et al [52]

To reduce environmental precipitating factors, which impair sleep and to support maintenance of circadian cycle.

Rivosecchi et al To provide cognitive stimuli [24] and to support reorientation ${ }^{\mathrm{b}}$

Mitchell et al [47] To support orientation and to provide cognitive stimulation

Zachary et al [59] To prevent functional/cognitive, sleep and visual/hearing impairment, and dehydration ized controlled trial
Prospective blinded

randomized trial

Pilot time-cluster randomized controlled study

Quasi-experimental

ICU

148 (I: 78, C: 69)

Prospective pre-experi- ICU mental

Prospective, observa- Medical ICU tional quality improvement project pre-post

Single center random- ICU

Retrospective
12

45 (I: 23, C: 22)

421 (I: 210, C: 211)

95 (I: 41, C: 54)

${ }^{\mathrm{a}}$ All patients are adults unless mentioned as pediatric patients.

${ }^{\mathrm{b}}$ With our minimal interpretation.

${ }^{\mathrm{C}} \mathrm{ICU}$ : intensive care unit.

${ }^{\mathrm{d}} \mathrm{I}$ : intervention group.

${ }^{\mathrm{e}} \mathrm{C}$ : control group.

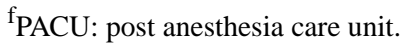

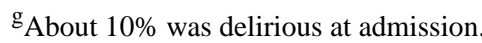

${ }^{\mathrm{h}}$ Only delirious patients.

${ }^{\mathrm{i}}$ Excluding intensive care unit patients. 


\section{Quality Scores of the Included Studies}

The assessed quality scores ranged from 1 [24,56] to 5 [32,36-39,46,48] (Multimedia Appendix 2). The average score was 3.258 (SD 1.264). A score lower than 3 was found in 10 studies [21,24,51-53,55-58,60]. Seven studies reached the maximum score of $5[33,36-39,46,48]$. The included studies were analyzed in 2 ways: first, by focusing on extracting the different types of technologies in the interventions, and second, by focusing on identifying strategies underlying these interventions.

Types of Technologies Currently Used for Preventing Delirium

A total of 31 technology-based interventions were identified (Table 2 and Table 3). Eight categories were distinguished based on the type of technology used. These categories are audio (7 studies), light (5 studies), video/video game (5 studies), virtual reality (VR) (3 studies), sleep aids (2 studies), communication support ( 2 studies), and others (2 studies). Technologies used as part of a multicomponent approach were grouped into a category called multiple components ( 5 studies). The identified technologies varied from simple (eg, earplugs, window blinds) to more advanced (eg, dynamic light, VR) ones. These technologies were used to complement conventional delirium treatments rather than replace them by reducing the negative (psychosocial) consequences of environmental factors and their effects on patient experiences. 
Table 3. The content and effects of technology-based nonpharmacological interventions.

\begin{tabular}{llllll}
\hline Study & Summary of the intervention & $\begin{array}{l}\text { Incidence of } \\
\text { delirium, } \\
P \text { value }\end{array}$ & $\begin{array}{l}\text { Duration of } \\
\text { delirium } \\
(\text { days })\end{array}$ & Direct $^{\mathrm{a}}$ & Indirect $^{\mathrm{b}}$ \\
& & Effectiveness & Key findings \\
\end{tabular}

\section{Audio: music/voice message}

Damshens Music therapy: Listening to light instruet al [40] mental music selected by a music expert for 45 minutes twice (once in the morning and once at night) for a day.

$\mathrm{I}^{\mathrm{c}}: 15(37.5 \%) \quad \mathrm{N} / \mathrm{A}^{\mathrm{e}} \quad \mathrm{No}^{\mathrm{f}} \quad \mathrm{Yes}^{\mathrm{g}}$
$\mathrm{C}^{\mathrm{d}}: 16(40 \%)$
$(P=.82)$

Lee et al Music intervention: A single 30-minute [39] session of listening to slow-beat music (60-80 bpm) selected by patients from predefined playlists through headphones in the presence of a nurse at the bedside. The study was conducted to explore the anxiety-reducing effect of the intervention.

Johnson et Music intervention: Listening to simple al [48] repetitive, self-selected music with slow tempo (60-80 bpm), low pitch, and repetitive rhythms for 60 minutes using an iPod and headsets, twice a day, over 3 days following admission.

Sharda et Confusion avoidance led by music proal [53] gram: On postoperative day 1, patients got a music player and headphones with a personalized playlist based on a music assessment. Listening for at least 20 minutes twice a day was recommended, but patients had autonomy over the ultimate dose and frequency.

Cheong et Creative music therapy: Spontaneous al [55] music making with musical instruments, playing familiar songs of patient's choice and music listening for 30 minutes once a day over 2 days. Based on individual's profile and response to music, a certified music therapist modified techniques to meet patients' need.

Byun et al Mother's recorded voice: Listening to [33] either the recorded a voice of mother (I1) or a stranger (I2) through noise-cancelling headphones at the end of a surgery. The prerecorded message with standardized text was repeated with 10second intervals and was continued until entering the postanesthesia care unit.

Munro et al Automated reorientation: During the first [49] 3 days at the intensive care unit, patients either received automated reorientation messages with a familiar (I1) or unfamiliar voice (I2) or no reorientation message at all (C). The message containing patient's name and information about the intensive care unit environment $(<2$ minutes long) was played during the day (9 AM to 4 PM).

\begin{tabular}{|c|c|c|c|c|}
\hline $\begin{array}{l}\text { I: } 17.8 \% \\
\text { C: } 28.7 \%\end{array}$ & N/A & No & No & $\begin{array}{l}\text { This program may impact inci- } \\
\text { dent delirium and optimize } \\
\text { postoperative pain and anxiety. }\end{array}$ \\
\hline
\end{tabular}

N/A

N/A

N/A

Yes

I1: $8(24.2 \%) \quad$ N/A $\quad$ Yes N/A

I2: $20(60.6 \%)$

$(P=.006)$

Delirium-free

I1:0.3

Yes

N/A

(0.48)

I1: 1.9 days

I2:0.6

(0.99)

$(0.84)$

I2: 1.6 days

C: 0.9

(1.07)

(1.28)

C: 1.6 days

(1.13)

(not signifi-

cant)
No significant difference between the control and test group in terms of incidence of delirium. Significantly lower use of 2 pain relievers (acetaminophen and diclofenac) in the test group.

Music intervention significantly reduced anxiety and stress-related measures (serum cortisol level, heart rate, visual analog scale for anxiety, etc) of mechanically ventilated intensive care unit patients.

No delirium incidence in both the control and test group. $\mathrm{Mu}$ sic intervention significantly improved the pathophysiological mechanisms that contribute to delirium, neurotransmitter imbalance, inflammation, and acute physiological stressors in the test group.

postoperative pain and anxiety.

This therapy can improve mood/emotion and engagement of patients with dementia and delirium.

Letting children listen to the sound of their mother in the recovery room reduced the incidence of emergence delirium.

Reorientation through automated messages increased the number of delirium-free days. A familiar voice was more effective than an unfamiliar voice in reducing delirium. 


\begin{tabular}{|c|c|c|c|c|c|c|}
\hline \multirow[t]{2}{*}{ Study } & \multirow[t]{2}{*}{ Summary of the intervention } & \multirow{2}{*}{$\begin{array}{l}\text { Incidence of } \\
\text { delirium, } \\
P \text { value }\end{array}$} & \multirow{2}{*}{$\begin{array}{l}\text { Duration of } \\
\text { delirium } \\
\text { (days) }\end{array}$} & \multicolumn{2}{|c|}{ Effectiveness } & \multirow[t]{2}{*}{ Key findings } \\
\hline & & & & Direct $^{\mathrm{a}}$ & Indirect $^{b}$ & \\
\hline \multicolumn{7}{|c|}{ Light: dynamic light/natural light } \\
\hline $\begin{array}{l}\text { Estrup et al } \\
\text { [58] }\end{array}$ & $\begin{array}{l}\text { Circadian light: Exposure to the circadi- } \\
\text { an light in which the amount of blue light } \\
\text { ( } 460-480 \mathrm{~nm} \text { ) changes over time like } \\
\text { natural light. The light intensity varied } \\
\text { from } 50 \text { lux to } 4000 \text { lux during daytime } \\
\text { (between 6:00 and 20:30) and there was } \\
\text { no blue light between } 23: 00 \text { and 6:00. } \\
\text { The exposure time of patients was varied } \\
\text { from at least } 24 \text { hours to their total stay. }\end{array}$ & $\begin{array}{l}\text { I: } 30 \\
\text { C: } 28\end{array}$ & $\begin{array}{l}\text { I: } 2.5 \\
(1-7) \\
\text { C: } 1.5 \\
(1-3) \\
(P=.41)\end{array}$ & No & N/A & $\begin{array}{l}\text { Circadian light did not have an } \\
\text { effect on the development of } \\
\text { delirium. }\end{array}$ \\
\hline $\begin{array}{l}\text { Pustjens et } \\
\text { al [60] }\end{array}$ & $\begin{array}{l}\text { Dynamic light: Exposure to an artificial } \\
\text { daylight system with light intensity peak } \\
\text { values of } 750 \text { lux at the eye level and a } \\
\text { color temperature ranging from } 2700 \mathrm{~K} \\
\text { to } 6550 \mathrm{~K} \text {. Patients were exposed as long } \\
\text { as possible during daytime. The overall } \\
\text { period varied from } 20 \text { hours to } 42.7 \\
\text { hours depending on the patient. }\end{array}$ & $\begin{array}{l}\text { I: } 20(5.4 \%) \\
\text { C: } 19(5.0 \%) \\
(P=.80)\end{array}$ & N/A & No & N/A & $\begin{array}{l}\text { Exposure to dynamic light did } \\
\text { not reduce the incidence of } \\
\text { delirium nor total hospital } \\
\text { length of stay. }\end{array}$ \\
\hline $\begin{array}{l}\text { Simons et } \\
\text { al [41] }\end{array}$ & $\begin{array}{l}\text { Dynamic light: Exposure to the circadian } \\
\text { light system with light intensity and col- } \\
\text { or temperature peaks of } 1700 \text { lux and } \\
4300 \mathrm{~K} \text { via conventional fluorescent } \\
\text { tubes between } 9: 00 \text { and } 16: 00 \text { except for } \\
11: 30 \text { and } 13: 30 \text { (intervention group) and } \\
\text { to the standard lighting settings of } 300 \\
\text { lux and } 3000 \mathrm{~K} \text { (control group) during } \\
\text { the intensive care unit stay of patients } \\
\text { (3-9 days). }\end{array}$ & $\begin{array}{l}\text { I: } 137(38 \%) \\
\text { C: } 123(33 \%) \\
(P=.16)\end{array}$ & $\begin{array}{l}\text { I: } 2(2-5) \\
\text { C: } 2(1-5) \\
(P=.87)\end{array}$ & No & N/A & $\begin{array}{l}\text { Dynamic light as a single inter- } \\
\text { vention did not reduce the cu- } \\
\text { mulative incidence and duration } \\
\text { of delirium in the test group. }\end{array}$ \\
\hline $\begin{array}{l}\text { Pothara- } \\
\text { jaroen et al } \\
{[42]}\end{array}$ & $\begin{array}{l}\text { Bright light: Treatment with bright light } \\
\text { therapy consisting of } 5000 \text { lux at } 1.4-\mathrm{m} \\
\text { distance from patient's face between } \\
\text { 9:00 and 11:00 for } 3 \text { days. Other treat- } \\
\text { ment data (nasal cannula oxygen, drugs } \\
\text { etc) were analyzed. }\end{array}$ & $\begin{array}{l}\text { I: } 2(6.45 \%) \\
\text { C: } 11 \\
(35.48 \%) \\
(P=.005)\end{array}$ & N/A & Yes & N/A & $\begin{array}{l}\text { Bright light therapy reduced the } \\
\text { incidence of delirium in the test } \\
\text { group. }\end{array}$ \\
\hline $\begin{array}{l}\text { Smonig et } \\
\text { al [54] }\end{array}$ & $\begin{array}{l}\text { Natural light exposure: Exposure to } \\
\text { natural light via windows from admis- } \\
\text { sion to the intensive care unit until dis- } \\
\text { charge (3-7 days). }\end{array}$ & $\begin{array}{l}\text { I: } 65(64 \%) \\
\text { C: } 55(71 \%) \\
(P=.28)\end{array}$ & $\begin{array}{l}\mathrm{I}: 3(1-6) \\
\mathrm{C}: 3(1-7) \\
(P=.43)\end{array}$ & No & Yes & $\begin{array}{l}\text { Admission to a single room } \\
\text { with natural light via windows } \\
\text { did not reduce the incidence of } \\
\text { delirium but a risk of agitation } \\
\text { episodes and hallucinations }\end{array}$ \\
\hline \multicolumn{7}{|c|}{ Video/video game: information/distraction } \\
\hline $\begin{array}{l}\text { Lee et al } \\
{[50]}\end{array}$ & $\begin{array}{l}\text { Preoperative video information: Informa- } \\
\text { tive videos that explain preoperative } \\
\text { procedures, operating room environment, } \\
\text { and intensive care unit environment on } \\
\text { the day prior to surgery. }\end{array}$ & $\begin{array}{l}\text { I: } 3(12 \%) \\
\text { C: } 5(20 \%) \\
(P=.26)\end{array}$ & N/A & No & Yes & $\begin{array}{l}\text { The intervention was not effec- } \\
\text { tive in reducing delirium inci- } \\
\text { dence but decreased the anxiety } \\
\text { levels. }\end{array}$ \\
\hline $\begin{array}{l}\text { Kim et al } \\
{[34]}\end{array}$ & $\begin{array}{l}\text { Video distraction and parental presence: } \\
\text { In the preoperative holding room before } \\
\text { surgery, provision of a 4-minute animat- } \\
\text { ed cartoon video (I1), parental presence } \\
\text { (I2), or a video plus parental presence } \\
\text { (I3). The primary study goal was to } \\
\text { compare the effect of video distraction, } \\
\text { parental presence, or combination of } \\
\text { both on the preoperative anxiety reduc- } \\
\text { tion. }\end{array}$ & $\begin{array}{l}\mathrm{I} 1: 13(38.2 \%) \\
\mathrm{I} 2: 13(39.4 \%) \\
\mathrm{I}^{\mathrm{e}}: 20 \\
(43.5 \%) \\
(P=.32)\end{array}$ & N/A & No & N/A & $\begin{array}{l}\text { All groups showed similar ef- } \\
\text { fect on the preoperative anxiety } \\
\text { and none of them significantly } \\
\text { reduced emergence delirium. }\end{array}$ \\
\hline
\end{tabular}




\begin{tabular}{|c|c|c|c|c|c|c|}
\hline \multirow[t]{2}{*}{ Study } & \multirow[t]{2}{*}{ Summary of the intervention } & \multirow{2}{*}{$\begin{array}{l}\text { Incidence of } \\
\text { delirium, } \\
P \text { value }\end{array}$} & \multirow{2}{*}{$\begin{array}{l}\text { Duration of } \\
\text { delirium } \\
\text { (days) }\end{array}$} & \multicolumn{2}{|c|}{ Effectiveness } & \multirow[t]{2}{*}{ Key findings } \\
\hline & & & & Direct $^{\mathrm{a}}$ & Indirect $^{\mathrm{b}}$ & \\
\hline $\begin{array}{l}\text { Rodriguez } \\
\text { et al [35] }\end{array}$ & $\begin{array}{l}\text { Video distraction using varying screen } \\
\text { size: Watching a movie in the preopera- } \\
\text { tive area and through the induction of } \\
\text { anesthesia. Patients chose from one of } \\
\text { the } 5 \text { preselected age-appropriate movies } \\
\text { using either a large bedside screen (I1) } \\
\text { or a small tablet (I2). One parent accom- } \\
\text { panied a patient. The average time spent } \\
\text { was } 3.8 \text { minutes (I1) and } 4.5 \text { minutes } \\
\text { (I2). The primary study goal was to } \\
\text { compare the effect of video distractions } \\
\text { in different screen sizes on anxiety reduc- } \\
\text { tion. }\end{array}$ & $\begin{array}{l}\text { I1: } 29.16 \% \\
\text { I2: } 30.8 \% \\
\text { (not signifi- } \\
\text { cant) }\end{array}$ & N/A & No & Yes & $\begin{array}{l}\text { The video distractions de- } \\
\text { creased the preoperative anxi- } \\
\text { ety, regardless of the size, with } \\
\text { parental presence at induction } \\
\text { of anesthesia. No effect was } \\
\text { found for the emergence deliri- } \\
\text { um rate. }\end{array}$ \\
\hline $\begin{array}{l}\text { Waszynski } \\
\text { et al [43] }\end{array}$ & $\begin{array}{l}\text { Simulated family presence and nature } \\
\text { scene: Two types of video intervention } \\
\text { for when agitation is present and the } \\
\text { family is not: watching a 1-minute fami- } \\
\text { ly video message plus usual care (I1) or } \\
\text { watching a 1-minute nature video plus } \\
\text { usual care (I2). The study goal was to } \\
\text { examine the effect of family video mes- } \\
\text { sage on agitation level. }\end{array}$ & N/A & N/A & N/A & Yes & $\begin{array}{l}\text { Both family video message and } \\
\text { nature video can decrease agita- } \\
\text { tion in delirious patients. }\end{array}$ \\
\hline $\begin{array}{l}\text { Dwairej et } \\
\text { al [36] }\end{array}$ & $\begin{array}{l}\text { Video game distraction and anesthesia } \\
\text { mask practice: Combination of video } \\
\text { distraction using a handheld video game } \\
\text { (1-2 minutes) before the transfer to oper- } \\
\text { ation room, anesthesia mask exposure, } \\
\text { and shaping intervention. During anesthe- } \\
\text { sia induction, parental presence is al- } \\
\text { lowed but not standardized. In the oper- } \\
\text { ating room, nonmedical talks occurred } \\
\text { to distract the child. The study goal was } \\
\text { to evaluate the effectiveness of the inter- } \\
\text { vention on the preoperative anxiety. }\end{array}$ & $\begin{array}{l}\text { I: mean } 11.06, \\
\text { SD } 3.97 \\
\text { C: mean } \\
10.25, \text { SD } \\
4.81 \\
(P=.30)\end{array}$ & N/A & No & Yes & $\begin{array}{l}\text { The intervention significantly } \\
\text { reduced anxiety. Yet, the re- } \\
\text { sults did not reveal statistically } \\
\text { significant difference in emer- } \\
\text { gence delirium scores. }\end{array}$ \\
\hline \multicolumn{7}{|c|}{ Virtual reality: information/distraction } \\
\hline $\begin{array}{l}\text { Eijlers et al } \\
\text { [37] }\end{array}$ & $\begin{array}{l}\text { Virtual reality exposure: Provision of a } \\
\text { 15-minute highly immersive virtual real- } \\
\text { ity experience of the operating theatre to } \\
\text { get familiarized with the environment } \\
\text { and general anesthesia procedures. The } \\
\text { virtual environment was computer-gen- } \\
\text { erated, interactive, and child-friendly. }\end{array}$ & $\begin{array}{l}\text { I: } 7.0(5.0- \\
9.0)^{\mathrm{f}} \\
\text { C: } 6.0(5.0- \\
9.0) \\
(P=.27)\end{array}$ & N/A & No & No & $\begin{array}{l}\text { This did not have a beneficial } \\
\text { effect on anxiety, pain, emer- } \\
\text { gence delirium, or parental } \\
\text { anxiety. }\end{array}$ \\
\hline $\begin{array}{l}\text { Ryu et al } \\
{[38]}\end{array}$ & $\begin{array}{l}\text { Preoperative immersive virtual reality } \\
\text { tour of operating theater: Provision of a } \\
\text { 4-minute virtual reality video for pedi- } \\
\text { atric patients showing the operating the- } \\
\text { ater and explaining the perioperative } \\
\text { process by using a popular animal char- } \\
\text { acter as a patient. The intervention was } \\
\text { provided } 1 \text { hour prior to entering the op- } \\
\text { erating room. The study goal was to ex- } \\
\text { amine the effect of the intervention on } \\
\text { reducing the preoperative anxiety. }\end{array}$ & $\begin{array}{l}\text { I: } 16(39 \%) \\
\text { C: } 14(36 \%) \\
(P=.77)\end{array}$ & N/A & No & Yes & $\begin{array}{l}\text { The intervention did not reduce } \\
\text { the incidence and severity of } \\
\text { emergence delirium, although } \\
\text { it was effective in alleviating } \\
\text { preoperative anxiety in chil- } \\
\text { dren. }\end{array}$ \\
\hline
\end{tabular}




\begin{tabular}{|c|c|c|c|c|c|c|}
\hline \multirow[t]{2}{*}{ Study } & \multirow[t]{2}{*}{ Summary of the intervention } & \multirow{2}{*}{$\begin{array}{l}\text { Incidence of } \\
\text { delirium, } \\
P \text { value }\end{array}$} & \multirow{2}{*}{$\begin{array}{l}\text { Duration of } \\
\text { delirium } \\
\text { (days) }\end{array}$} & \multicolumn{2}{|c|}{ Effectiveness } & \multirow[t]{2}{*}{ Key findings } \\
\hline & & & & Direct $^{\mathrm{a}}$ & Indirect $^{\mathrm{b}}$ & \\
\hline $\begin{array}{l}\text { Suvajdzic } \\
\text { et al [57] }\end{array}$ & $\begin{array}{l}\text { Patient-centered virtual reality system: } \\
\text { Intervention consisting of } 2 \text { sessions } \\
\text { (session } 2 \text { was held at least } 24 \text { hours after } \\
\text { session 1): (1) a video instructing pa- } \\
\text { tients to enjoy the movie by moving their } \\
\text { heads to look around, followed by a 5- } \\
\text { 10-minute guided meditation in virtual } \\
\text { nature scenes for breath control (Relax } \\
\text { VR). (2) plaving either Relax VR or }\end{array}$ & I: $0(0 \%)$ & N/A & N/A & No & $\begin{array}{l}\text { The interventions did not result } \\
\text { in clinically significant changes } \\
\text { in pain, sleep, or vital signs. It } \\
\text { seems likely that greater expo- } \\
\text { sure to virtual reality is more } \\
\text { likely to produce a meaningful } \\
\text { effect on patient physiology } \\
\text { and sleep quality. }\end{array}$ \\
\hline
\end{tabular}

\section{Sleep aids}

Demoule et Earplugs and eye masks: Use of earplugs al [44] and eye masks every night between 10 $\mathrm{PM}$ and $8 \mathrm{AM}$ from inclusion until ICU discharge (average 7 days). The study goal was to evaluate the impact of the intervention on sleep architecture in intensive care unit patients.

Van de Pol Nocturnal sound-reduction protocol: A et al [19] protocol focusing on reducing noise in the night, for example, speaking and laughing quietly in the lobby, minimizing alarm volume, closing the door when the patient is not delirious, and providing earplugs at night. One month of implementation phase.

\author{
I: $2(7 \%)$ \\ C: $2(6 \%)$ \\ $(P>.99)$
}

N/A

N/A

Yes

Slope of delirium incidence

N/A

I: $-2.79 \%$

$(P=.02)$

C: $0.91 \%$

$(P=.37)$

Difference:

$-3.70 \%$ per

time period

$(P=.02)$

\section{Communication aids}

Garry et al Eye-tracking devices: Usage sessions (45 [56] $\mathrm{min} / \mathrm{session}, 5$ sessions on consecutive weekdays) were given, during which patients were prompted to spell out notes, indicate their needs via picture sets, and play simple memory games. Patients were permitted to communicate with family, nursing staff, and physicians outside the training sessions.

Bott et al Bedside digital care coach avatar: 24[21] hour psychosocial and health care support through an embodied conversational agent with an appearance of animated animal avatar. It checks patient status, assists communication, and offers psychological support during their stay at medical and surgical units (3-6 days). The average time spent with the embodied conversational agent was 61 minutes per day.

\section{Others}

Lin et al Eyepatch for visual preconditioning:

[46] Preventive treatment for pediatric patients undergoing ophthalmic surgery consisted of covering the eye with an eyepatch for at least 3 hours one day before surgery.

\section{Day 1: 4 \\ N/A \\ N/A \\ Yes}

$(33 \%)$

Day 2: $1(8 \%)$

Day $3 /$ on-

ward: 0
I: pre 12

$(41 \%) /$ post 1

(3\%)

C: pre6

$(13 \%) /$ post3

$(6 \%)$

$(P<.01 / .25)$

N/A Yes Yes

$\begin{array}{llll}\text { I: } 15(16.9 \%) & \text { N/A } & \text { Yes } & \text { Yes } \\ \text { C: } 40(44.4 \%) & & & \\ (P<.001) & & & \end{array}$

Interventions resulted in reduced long awakenings and increased deep sleep duration. Possibly the effect was at least partially counteracted by the discomfort of wearing the devices.

The protocol reduced the incidence of delirium. It significantly reduced delirium risk factors such as perceived nighttime noise and the use of sleep medication. Reported sleep quality was not improved.

The use of an eye-tracking device positively affected patients' happiness and ability to participate; however, it did not show a significant effect on patients' confusion level or frustration.

The use of the care coach avatar during hospitalization can reduce the frequency of delirium, loneliness, and falls among diverse hospitalized older adults. 


\begin{tabular}{|c|c|c|c|c|c|c|}
\hline \multirow[t]{2}{*}{ Study } & \multirow[t]{2}{*}{ Summary of the intervention } & \multirow{2}{*}{$\begin{array}{l}\text { Incidence of } \\
\text { delirium, } \\
P \text { value }\end{array}$} & \multirow{2}{*}{$\begin{array}{l}\text { Duration of } \\
\text { delirium } \\
\text { (days) }\end{array}$} & \multicolumn{2}{|c|}{ Effectiveness } & \multirow[t]{2}{*}{ Key findings } \\
\hline & & & & Direct $^{\mathrm{a}}$ & Indirect $^{\mathrm{b}}$ & \\
\hline \multirow{6}{*}{$\begin{array}{l}\text { Giraud et } \\
\text { al [45] }\end{array}$} & \multirow{6}{*}{$\begin{array}{l}\text { Structured mirrors intervention: Proto- } \\
\text { col-driven mirrors intervention consist- } \\
\text { ing of different mirrors to provide visual } \\
\text { feedback about the environment as a re- } \\
\text { orientation tool and to support self- } \\
\text { awareness and explanation of medi- } \\
\text { cal/nursing procedures. The unit of ran- } \\
\text { domization was a 2-week time period }\end{array}$} & \multirow{6}{*}{$\begin{array}{l}\text { I: } 20(17 \%) \\
\text { C: } 17(16 \%) \\
(P=.71)\end{array}$} & I: 1 (IQR & No & Yes & \multirow{6}{*}{$\begin{array}{l}\text { Use of the mirror intervention } \\
\text { did not reduce delirium but im- } \\
\text { proved factual memory encod- } \\
\text { ing. }\end{array}$} \\
\hline & & & $1-3$ [range & & & \\
\hline & & & & & & \\
\hline & & & $\begin{array}{l}\text { C: } 2 \text { (IQR } \\
1-8 \text { [range }\end{array}$ & & & \\
\hline & & & $1-13])$ & & & \\
\hline & & & $(P=.40)$ & & & \\
\hline
\end{tabular}

\section{Multiple components}

Arbabi et Environmental changes and liaison edual [51] cation: Environment with proper time cues, appropriate lighting for the time of the day during intensive unit care stay (average about 5 days). Further, allowing interactions with family members and medical staff, giving vision and hearing aids, preventing dehydration, and encouraging early mobilization. Training for medical staff on delirium management.

Tovar et al Environment with reduced environmental [52] stressors: Nursing care guide to reduce environmental stressors such as noise and continuous artificial light. Provision of active interactions with family members and medical staff, cognitive/sensory stimuli, and information about the environment. The posttest was performed after the guideline had been applied for 5 days.

Rivosecchi Nonpharmacological protocol: Nursing et al [24] education bundled into the protocol consisting of music, opening blinds, reorientation and cognitive stimulation, eye and ear protocol during intensive care unit stay (median 188.3 hours-control group, and 153.5 hours-intervention group).

Mitchell et Multicomponent family-delivered interal [47] vention: Family intervention consisting of orientation (memory clues: family pictures etc), therapeutic engagement (cognitive stimulation: discussing current family life events etc), and sensory (glasses, hearing aids in place/working). The intervention group was enrolled for a median of 5 days and the family members were asked to deliver the intervention at least once a day. The study goal was to assess the feasibility and acceptability of the intervention for designing a larger randomized controlled trial.

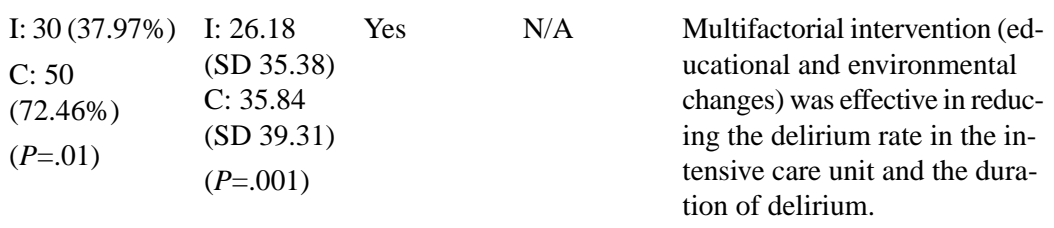

I: $3(6.12 \%) \quad$ N/A $\quad$ Yes $\quad$ N/A

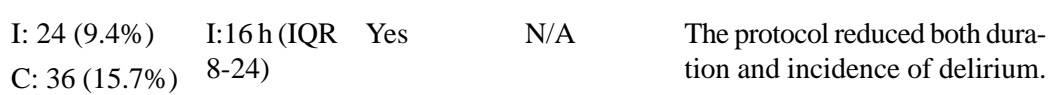

$(P=.04) \quad \mathrm{C}: 20 \mathrm{~h}$

(IQR 9.5-

37)

$(P<.001)$

I: $17(59 \%)$

I: $1.0(2) \quad$ No

N/A

C: $18(56 \%)$

C: 1.0 (2)

$(P=.87)$

$(P=.60)$
Multicomponent intervention focusing on reducing precipitating environmental factors was effective in reducing delirium incidence and improving sleep.

\begin{abstract}
Multicomponent family-delivered intervention was not effective in reducing delirium incidence nor days of delirium.
\end{abstract}




\begin{tabular}{|c|c|c|c|c|c|c|}
\hline \multirow[t]{2}{*}{ Study } & \multirow[t]{2}{*}{ Summary of the intervention } & \multirow{2}{*}{$\begin{array}{l}\text { Incidence of } \\
\text { delirium, } \\
P \text { value }\end{array}$} & \multirow{2}{*}{$\begin{array}{l}\text { Duration of } \\
\text { delirium } \\
\text { (days) }\end{array}$} & \multicolumn{2}{|c|}{ Effectiveness } & \multirow[t]{2}{*}{ Key findings } \\
\hline & & & & Direct $^{\mathrm{a}}$ & Indirect $^{b}$ & \\
\hline $\begin{array}{l}\text { Zachary et } \\
\text { al [59] }\end{array}$ & $\begin{array}{l}\text { Hospital elder life program interven- } \\
\text { tions: Geriatric intervention program } \\
\text { consisting of reorientation, social stimu- } \\
\text { lation, music therapy, games, mindful- } \\
\text { ness relaxation, mobilization, visual/hear- } \\
\text { ing aids, sleep aids, and nutrition sup- } \\
\text { port. Volunteer interventions were } 3 \\
\text { times a day, which took } 20-30 \text { minutes } \\
\text { each time. }\end{array}$ & N/A & N/A & N/A & Yes & $\begin{array}{l}\text { This program reduced } 30 \text {-day } \\
\text { readmissions and hospital } \\
\text { length of stay in the } 70-85 \\
\text { years age group. }\end{array}$ \\
\hline
\end{tabular}

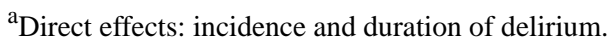

${ }^{\mathrm{b}}$ Indirect effects: length of stay or delirium risk factors, including but not limited to pain, anxiety, stress, mood, agitation, and sleep deprivation.

${ }^{\mathrm{c}} \mathrm{I}$ : intervention group.

${ }^{\mathrm{d}} \mathrm{C}$ : control group.

${ }^{\mathrm{e}} \mathrm{N} / \mathrm{A}$ : not applicable.

${ }^{\mathrm{f}}$ No significant positive effect.

${ }^{\mathrm{g}}$ Significant positive effect.
}

Of the 31 identified studies, 23 studies analyzed the effect of the interventions on direct delirium-related outcome measures (incidence and duration of delirium). The other 8 studies only assessed indirect outcome measures (eg, length of stay, precipitating risk factors of delirium such as anxiety). Of the 23 studies that evaluated direct delirium-related outcome measures, 9 studies showed a significant effect on decreasing either or both incidence and frequency of delirium. The interventions in these studies involved diverse technologies across the categories, that is, audio [33,49], light [42], sleep aids [19], communication support [21], others [46], and multiple components $[24,51,52]$. Of the 14 studies without significant effect on direct outcome measures, 8 studies, however, showed significant effects on delirium risk factors or symptoms, including pain [40], anxiety [35,36,38,50], agitation [54], hallucination [54], and factual memory encoding [45]. Six of the 8 studies using diverse technology-based interventions showed a significant effect on indirect outcome measures, including anxiety [39], agitation [43], sleep deprivation [44], or ICU readmission [59]. The technologies used in these studies were audio [39,48,55], video/video game [43], sleep aids [44], and multiple components [59]. It is notable that across all technology categories, significant positive effects were found on either or both direct and indirect delirium outcome measures. An explanation and further analysis of each category is given as follows.

\section{Audio}

The interventions using audio had either music or prerecorded voice messages. Music interventions involved, in general, slow tempo music with a duration of 20 minutes to 1 hour. The music was provided 2 or 3 times a day by using a television audio system or headset. These interventions aimed at addressing anxiety [39,53], mood [55], pain [40,53], and engagement [55] for adult patients. Across these interventions, we found differences in the level of personalization and autonomy: the level of personalization varied from the provision of music preselected by a music expert to the creation of a music playlist based on a patient's own choice and the level of autonomy ranged from patients listening to music with dose and frequency predecided by a researcher to patients deciding on dose and frequency. Interestingly, delirium incidence was reduced in the study with personalized music allowing patients autonomy [53]. While the majority of studies used a passive format such as music listening, 1 study used a participatory format providing an interactive music therapy and showed significant improvement in mood and engagement [55]. Prerecorded voice messages contained mainly patient's name and information about the care environment using either a familiar or unfamiliar voice. These interventions aimed to provide reorientation and a feeling of comfort. Two studies were carried out with different patient age groups: one with pediatric patients and the other with adult patients. The use of a prerecorded voice message reduced direct delirium outcome in both groups $[33,49]$. Likewise, one of the studies showed that a familiar voice was more effective than an unfamiliar one [49].

\section{Light}

The interventions involving light used either a specially made light therapy system for dynamic/bright light or natural light through windows. Dynamic light interventions provided light consisting of diverse intensities (ranging from 50 lux to 4000 lux) and color temperatures (ranging from $2700 \mathrm{~K}$ to $6550 \mathrm{~K}$ ) in the environment of patients $[41,58,60]$. The bright light intervention used high intensity of light (5000 lux) for 2 hours a day [42] while the natural light intervention used natural light coming through windows [54]. All studies aimed at improving the patients' circadian rhythm and were only tested on adult patients. Only the bright light intervention showed an effect on reducing the incidence of delirium [42]. Possibly, most of the current light interventions are not effective in reducing direct delirium outcomes. Another possible explanation for why few studies found an effect on reducing incidence of delirium might relate to the amount of light (intervention) that patients actually received. In most studies, for example, the actual light intensity at patients' eye level was not specified or the definite exposure time to light of each patient was not guaranteed as sedative patients were included who had their eyes closed $[54,58,60]$. 


\section{Video/Video game}

The interventions using video/video games were used for providing either information about the medical procedure prior to a surgery or distractions with various contents, including age-appropriate programs (eg, cartoons), family messages, or nature scenes through a handheld tablet or a specially made bedside screen. These interventions aimed to address anxiety or agitation and were effective in decreasing anxiety or agitation in all studies with either pediatric or adult patients [34-36,43,50]. Regarding direct delirium outcome measures, none of the studies showed a significant effect [34-36,50].

\section{VR Technology}

The interventions using VR technology provided either information about medical procedures, distraction, or sensory stimulation for patients. VR interventions used a head-mounted device and the VR content varied from a guided tour to the operating theatre, to the virtual scenes of real-world locations. The interventions were mainly used to address anxiety or to support restorative effect for both pediatric and adult patients $[37,38,57]$. The effects of using VR to provide information (a preoperative VR tour to the operating theatre) differed in the studies. Of the two, 1 study showed a significant effect on reducing the anxiety of pediatric patients [38]. For none of these studies, the use of VR resulted in any effect on delirium-related outcome measures [37,38,57].

\section{Sleep Aids}

The interventions related to sleep aids were wearable devices such as earplugs and eye masks $[19,44]$, and environmental modifications such as closing doors and window blinds were applied [19]. They aimed at reducing noise and light during nighttime to improve the sleep quality of adult patients. The application of both wearables and environmental modifications showed an effect on reducing the incidence of delirium [19]. Moreover, the use of a wearable showed an improvement in sleep quality [44]. It is notable that this study also highlights the potential negative side-effects of using wearables due to discomfort experienced by vulnerable patients.

\section{Communication Supports}

The technologies used for communication supports were a conversational agent [21] and an eye-tracking device [56]. They assisted adult patients to express their needs or to participate in psychosocial activities. Both types improved the psychological well-being of patients by increasing happiness and the ability to participate and by reducing loneliness. The conversational agent was used as a digital care coach providing communication means, human interactions, and companionship. This intervention reduced the frequency of delirium [21].

\section{Others}

In this category, we found rather simple forms of technologies used for diverse purposes: an eyepatch for experiencing what will happen after surgery [46] and a structured mirror to provide patients cognitive stimuli as a means to support mobilization and communication [45]. The eyepatch was used for pediatric patients and was effective in reducing emergence delirium [46]. The structured mirror intervention was for adult patients and improved their factual memory encoding [45].

\section{Multiple Components}

Some interventions involved more than one technology as part of a nonpharmacological bundle for adult patients. Environmental modifications for noise reduction, cognitive stimulation, and reorientation reduced delirium incidences in 3 studies [24,51,52]. Zachary et al [59] had a similar focus and showed an effect on reducing the 30 -day readmission. In a small feasibility study, no significant effect was found on direct delirium outcome measures for the simple technology-based intervention involving families throughout different therapies such as orientation and cognitive stimulation [47].

\section{Seven Pathways to Delirium Prevention}

Fourteen strategies to prevent delirium were identified from the technology-based interventions of the included studies (see Multimedia Appendix 3 for the 14 strategies used in the included studies and see Table 4 for full description of the 14 strategies). 
Table 4. Descriptions of the 14 strategies.

\begin{tabular}{|c|c|c|}
\hline Strategy & Explanation & Example \\
\hline Cognitive stimulation and training & $\begin{array}{l}\text { Stimulating patient's brain activity to maintain and improve their cogni- } \\
\text { tive capability and executive functions such as attention, } \\
\text { memory, reasoning, and language. }\end{array}$ & Music, book \\
\hline Companionship & $\begin{array}{l}\text { Providing patients a sense of consistent social presence as a means to } \\
\text { combat social isolation and loneliness. }\end{array}$ & Digital agent \\
\hline Contextual cue (reorientation) & $\begin{array}{l}\text { Providing patients contextual information such as time, date, and place } \\
\text { to minimize confusion and anxiety coming from not knowing what's } \\
\text { going on and feeling lost }\end{array}$ & Automated voice message, clock \\
\hline Daytime awakening & $\begin{array}{l}\text { Supporting patients to stay physically and mentally activated during day } \\
\text { so they can become tired enough to sleep at night }\end{array}$ & Dynamic light \\
\hline Distraction & $\begin{array}{l}\text { Redirecting patient's focus away from distressing situations/conditions } \\
\text { such as pain, discomfort, fear, and anxiety }\end{array}$ & Music, video, virtual reality \\
\hline Early mobilization & $\begin{array}{l}\text { Encouraging patients to move their bodies early enough to prevent } \\
\text { muscle loss and other complications caused by lack of physical movement }\end{array}$ & Structured mirror \\
\hline Easier communication & $\begin{array}{l}\text { Providing a means for patients to better express their needs especially } \\
\text { when they are mechanically ventilated }\end{array}$ & Eye-tracking device \\
\hline Engagement & $\begin{array}{l}\text { Encouraging patients to be interested in and to be involved with what is } \\
\text { happening }\end{array}$ & Participatory music therapy \\
\hline Familiarity & $\begin{array}{l}\text { Providing something that patients feel familiar with to help them feel } \\
\text { safe, at ease, and calm }\end{array}$ & $\begin{array}{l}\text { Mother's voice, personalized music } \\
\text { list }\end{array}$ \\
\hline Good night sleep & $\begin{array}{l}\text { Providing an environment that facilitates sleeping by removing disturbing } \\
\text { elements such as sound and light noise and by adding elements enhancing } \\
\text { patient comfort and relaxation }\end{array}$ & Ear plugs \\
\hline Human (social) interaction & $\begin{array}{l}\text { Providing patients warm human (-like) interactions to stimulate them } \\
\text { socially and to help them feel being involved and being cared for }\end{array}$ & Digital agent \\
\hline Psychological preparation & $\begin{array}{l}\text { Helping patients to feel prepared and confident by informing them what } \\
\text { will happen in advance. }\end{array}$ & Virtual tour to the operation room \\
\hline Soothing elements & $\begin{array}{l}\text { Helping patients to calm down and to manage stress and anxiety by } \\
\text { providing an activity or environment that is soothing }\end{array}$ & Music, nature video \\
\hline
\end{tabular}

Subsequently, the 14 strategies were clustered into 7 pathways by using a thematic analysis approach (Figure 2). As such, the 7 pathways might provide directions toward technology-based interventions for delirium prevention. The 7 pathways and a short description of each pathway are as follows:

1. Restore the circadian rhythm: helping patients to find a normal sleep-wake cycle to prevent sleep deprivation.

2. Activate the body: supporting patients to regain physical strength and endurance.

3. Activate the mind: supporting patients to prevent cognitive decline, restore cognitive function, and minimize confusion, which can cause negative emotions such as anxiety, agitation, and aggression.

4. Induce relaxation: helping patients to stay in a positive psychological state, which prevents emotional distress, makes it easier to cope with their situation, and improves the patients' physical state (eg, through better sleep).

5. Provide a sense of security: supporting patients in feeling reassured and safe so that they can easily handle stress and emotional distress such as anxiety and fear that originate mainly from uncertainty and unfamiliarity.

6. Provide a sense of control: supporting patients by enhancing autonomy, empowerment, and control over anxiety.

7. Provide a sense of being connected: supporting patients to feel connected and socially engaged to prevent loneliness, depression, and anxiety.

Three of the 7 pathways outlined above, that is, Restore the Circadian Rhythm, Activate the Body, and Activate the Mind, are in line with strategies recommended in the ABCDEF bundle [16]. The other pathways are not directly linked, yet are associated with important predictors of well-being used in psychology: Induce Relaxation links to coping strategies [61] and Provide a Sense of Security, Control, and Being Connected are related to the universal psychological needs, which are security [62], dominance [63], and relatedness [62]. The 7 pathways, therefore, cover a broad range of delirium prevention strategies correlating physical, cognitive, and emotional aspects as shown in Figure 2. 
Figure 2. Overview of the 14 strategies grouped into 7 pathways of delirium prevention that are used in technology-based interventions.

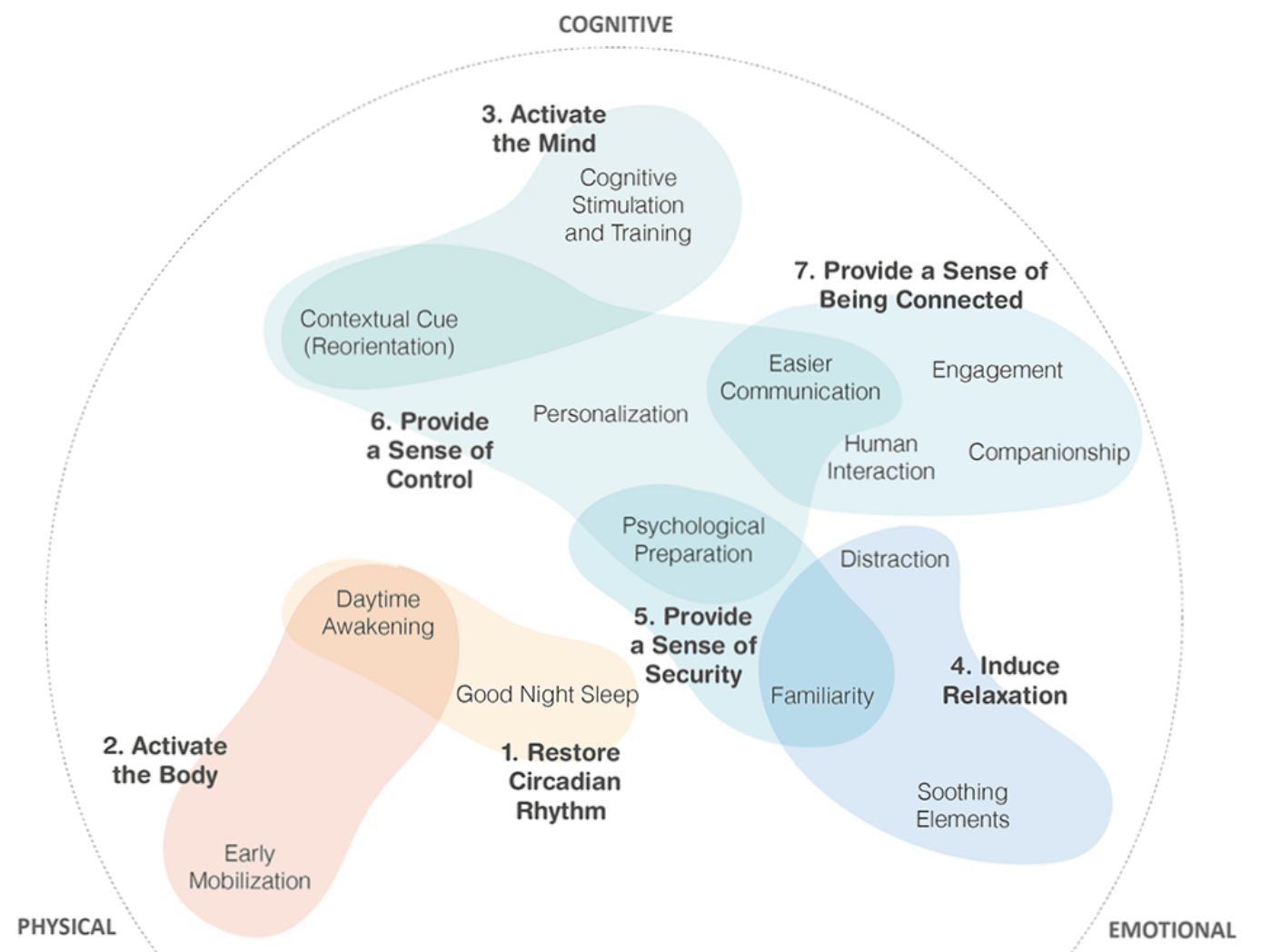

\section{Discussion}

\section{Overview}

The results of this review provided an overview and characteristics of technology-based interventions that have been used to prevent and reduce delirium. We also summarized the related strategies into 7 pathways. These 7 pathways include key elements for developing technology-based interventions for delirium prevention. From our analysis of the included studies and technologies, we next discuss the limitations and opportunities for future research.

\section{Limitations in the Current Technology Use for Preventing Delirium}

First, most technology-based interventions addressed only one or a few delirium risk factors. For instance, interventions that used a dynamic light system [41,60] aimed to improve the patients' sleep-wake cycle while interventions, including video distraction $[34,35,43]$, aimed to reduce the anxiety of the patients. Such approaches are not in line with the frequently recommended multicomponent approach, which effectively targets the multifactorial origin of delirium [15]. Second, most technology-based interventions were more momentary than continuous solutions. Although the length of stay in the ICU should be kept as short as possible, it can last from days to weeks. During this period, depending on the severity of their illness, patients are going through various clinical and emotional phases and their needs are changing respectively. During various activities (eg, clinical checkup, therapy session, cleaning, resting, family visit), patients can experience diverse feelings (eg, anxiety, fear, tiredness, worrying, relaxed, cheerful) and have different corresponding needs. In contrast to the heterogeneity of activities and patients' needs throughout their ICU stay, the majority of the included studies focused on a short period of time. For instance, the video and video game interventions were usually planned for less than 5 minutes [34-36,43,50], and the VR interventions were used for less than 15 minutes [37,38,57]. In order to minimize delirium risk factors, it is important to understand the needs and concerns of patients throughout their whole ICU stay and to develop preventive solutions that are more continuous and seamless. Importantly, knowledge as how to develop and implement a continuous solution throughout the ICU stay of patients is missing as none of the reviewed studies evaluated it. Third, only a limited number of studies focused on the use of technology for improving the patients' environment. Despite the negative influences of the stressors in the current ICU environment, such as overload of light and noise [64,65] on patients' clinical progress, only a few studies $[41,51,52,58,60]$ aim at optimizing the ICU environment. In contrast, most technologies used as interventions added extra sensory burden to the patients. Last, 
the effect of some technologies can be improved by a more thorough understanding of (vulnerable) patients and context-dependent needs. Understanding the patient's needs is crucial for delivering high-quality care. However, sometimes, the implementation of technology can be challenging and might result in a suboptimal match with the patients and context. For instance, in the study of bright light therapy, patients were sedated and had their eyes closed and this resulted in insufficient amount of light exposure [41]. The use of wearable sleep-aid devices (earplugs and eye masks) by ICU patients can lead to potential discomfort, thereby limiting the effectiveness of the intervention [44].

\section{Further Development of Technology-Based Interventions for Preventing Delirium}

Despite the limitations of current technology-based interventions, the potential of technology in delirium prevention is promising [20]. Reflecting on the identified limitations, the following recommendations are proposed for the future design and development of technology-based interventions for delirium prevention. First of all, technology should not only support physical and cognitive functions but also support psychological and emotional needs. In the analysis, the proposed 7 pathways described existing approaches for delirium prevention, which cover multifaceted needs of patients. Yet, comparing the number of related strategies and studies included in each pathway, it is notable that, in general, there are far more technology-based interventions aiming to support functions than to support needs. To take a more comprehensive approach, further development of technologies should aim at meeting patients' needs by, for instance, providing a means to allow them more control over their situation, feel relaxed, safe, and connected. Some examples are an interaction device to enable ventilated patients to easily express their needs using gestures [66], a robotic pet that lets patients cuddle and helps them feel calm [67], or an intelligent alarm system contributing to a relaxing environment for ICU patients by controlling and harmonizing alarm sounds [68]. Another way to meet patients' emotional and psychological needs can be found in the provision of (multi-) sensorial and cognitive stimuli. For instance, aromatherapy can be a way to support patients to feel relaxed through sensorial stimuli combining pleasant tactile pressure and aromatic fragrance [69]. For the stimuli, using nature elements can be an interesting candidate as exemplified by previous cases $[43,57]$ and other applications: examples are a VR therapy showing various nature sceneries [70] and a geriatric care environment adapting nature elements [71] to generate relaxation [70,71], increase social engagement, and reduce restlessness [71]. Second, technology could create a healing environment for patients: a more context-aware, personalized, and adaptive ICU. Despite emerging interest in patient-centered care, this review showed that such interactive technology is rare in the current ICU environment. Patient-centered care recognizes a patient as a unique individual and stresses the importance of care tailored to patients' specific preferences, needs, and values [72-74]. In order to better adapt patient-centered care, technology should be evolved in a way that (1) it allows patients to take a more active role in their care process, for instance, by enabling them to be explicit about their specific needs and (2) enables a care environment and service system to provide real-time interventions adapted to the patients' profiles and their changing status/needs. Advances in technologies have made this feasible. Next to the modified ICU room [20] and the conversational agent [21] described in the introduction, the intelligent ICU concept enables autonomous monitoring of patients and the ICU environment over time by using pervasive sensing [75]. Previously we pointed out that there were too few technologies aiming at improving patients' environment despite its significant influence on patients. Luetz et al [20] emphasized the potential of environment-related innovations, arguing that the ICU should be considered as a treatment tool. In order to design a healing environment, future technology-based interventions should reinforce the main ingredients of patient-centered care: context-awareness, personalization, and adaptability.

\section{Study Limitations}

This study has some limitations. First, this review was conducted between 2015 and 2020 to focus on state-of-the-art technologies used for preventing and reducing delirium. Therefore, some technologies that might have been introduced in the studies published before 2015 and have not been studied since then were not included in this review. Second, the search strategy made use of the combination of keywords describing different types of technologies and not the keyword "technology" as this was not widely used in literature on delirium prevention and reduction. Although we tried to cover all the existing technology-related keywords, this search strategy might have left out some very rare types of technologies. Third, the 7 pathways were made based on the included studies only. Therefore, some approaches and strategies from the studies, which did not meet our criteria, were not included, such as approaches and strategies related to pharmacological interventions or delirium detection only.

\section{Conclusions}

In this review, we provided an overview of technology-based interventions and proposed the 7 pathways to delirium prevention based on evidence-based studies. These insights can be considered as starting points for transforming ICUs into a healing environment, which might be well one of the most powerful nonpharmacological technology-based interventions for preventing delirium. Further research should generate a more in-depth and complete understanding of the key components of a healing environment for patients and on designing and developing technologies that can actualize it.

\section{Acknowledgments}

We would like to thank Thomas Falck, MSc (Philips Research) and Dr Ir Hanneke Becht (University of Twente) for helping with the development of the search strategy, Prof Dr Sophia de Rooij (University Medical Center Groningen) for advising on the 
formulation of the search scope, and Meyke Roosink (Philips) and Benedetta Lusi (University of Twente) for participating in the clustering session.

\section{Authors' Contributions}

CMK contributed to planning, screening, reading full text, and acquiring/analyzing/interpreting data. EMvdH contributed to screening, acquiring data, reading full text, and revising the results of data analysis/interpretation. TJLvR and GJV reviewed the results of data analysis/interpretation. GDSL conceptualized and reviewed the results of data analysis/interpretation. All authors contributed to drafting the manuscript or revising it critically for important intellectual content. All authors read and confirmed the final version of the manuscript and agreed to be accountable for all aspects of the work in ensuring that questions related to the accuracy or integrity of the work are appropriately investigated and resolved.

\section{Conflicts of Interest}

This study is part of the Digital Nature project that received funding from the Top Technology Twente Connecting Industry program (TKI Topsector HTSM), which is partially funded (paid to institution) by Philips. CMK is employed by the University of Twente through this fund. EMvdH is employed fully by Philips. The remaining authors do not have a conflict of interest to declare.

\section{Multimedia Appendix 1}

Search strategy.

[PDF File (Adobe PDF File), 74 KB-Multimedia Appendix 1]

\section{Multimedia Appendix 2}

Quality assessment.

[PDF File (Adobe PDF File), 147 KB-Multimedia Appendix 2]

\section{Multimedia Appendix 3}

Fourteen strategies used in the included studies.

[PDF File (Adobe PDF File), 229 KB-Multimedia Appendix 3]

\section{References}

1. Morandi A, Jackson JC, Ely EW. Delirium in the intensive care unit. Int Rev Psychiatry 2009 Feb;21(1):43-58. [doi: 10.1080/09540260802675296] [Medline: 19219712]

2. Page VJ, Navarange S, Gama S, McAuley DF. Routine delirium monitoring in a UK critical care unit. Crit Care 2009;13(1):R16 [FREE Full text] [doi: 10.1186/cc7714] [Medline: 19203391]

3. Ely EW, Inouye SK, Bernard GR, Gordon S, Francis J, May L, et al. Delirium in mechanically ventilated patients: validity and reliability of the confusion assessment method for the intensive care unit (CAM-ICU). JAMA 2001 Dec 05;286(21):2703-2710. [doi: 10.1001/jama.286.21.2703] [Medline: 11730446]

4. Spronk PE, Riekerk B, Hofhuis J, Rommes JH. Occurrence of delirium is severely underestimated in the ICU during daily care. Intensive Care Med 2009 Jul;35(7):1276-1280 [FREE Full text] [doi: 10.1007/s00134-009-1466-8] [Medline: 19350214]

5. Faria RDS, Moreno R. Delirium in intensive care: an under-diagnosed reality. Rev Bras Ter Intensiva 2013;25(2):137-147 [FREE Full text] [doi: 10.5935/0103-507X.20130025] [Medline: 23917979]

6. Salluh JI, Soares M, Teles JM, Ceraso D, Raimondi N, Nava VS, Delirium Epidemiology in Critical Care Study Group. Delirium epidemiology in critical care (DECCA): an international study. Crit Care 2010;14(6):R210 [FREE Full text] [doi: 10.1186/cc9333] [Medline: 21092264]

7. Girard TD, Jackson JC, Pandharipande PP, Pun BT, Thompson JL, Shintani AK, et al. Delirium as a predictor of long-term cognitive impairment in survivors of critical illness. Critical Care Medicine 2010;38(7):1513-1520. [doi: $10.1097 / \mathrm{ccm} .0 \mathrm{~b} 013 \mathrm{e} 3181 \mathrm{e} 47 \mathrm{be} 1]$

8. Ely EW, Shintani A, Truman B, Speroff T, Gordon SM, Harrell FE, et al. Delirium as a predictor of mortality in mechanically ventilated patients in the intensive care unit. JAMA 2004 Apr 14;291(14):1753-1762. [doi: 10.1001/jama.291.14.1753] [Medline: $\underline{15082703}$ ]

9. Vasilevskis EE, Chandrasekhar R, Holtze CH, Graves J, Speroff T, Girard TD, et al. The Cost of ICU Delirium and Coma in the Intensive Care Unit Patient. Medical Care 2018;56(10):890-897. [doi: 10.1097/mlr.0000000000000975]

10. Rubin FH, Bellon J, Bilderback A, Urda K, Inouye SK. Effect of the Hospital Elder Life Program on Risk of 30-Day Readmission. J Am Geriatr Soc 2018 Jan;66(1):145-149 [FREE Full text] [doi: 10.1111/jgs.15132] [Medline: 29086425]

11. Zamoscik K, Godbold R, Freeman P. Intensive care nurses' experiences and perceptions of delirium and delirium care. Intensive Crit Care Nurs 2017 Jun;40:94-100. [doi: 10.1016/j.iccn.2017.01.003] [Medline: 28259522] 
12. Leslie DL, Marcantonio ER, Zhang Y, Leo-Summers L, Inouye SK. One-year health care costs associated with delirium in the elderly population. Arch Intern Med 2008 Jan 14;168(1):27-32 [FREE Full text] [doi: 10.1001/archinternmed.2007.4] [Medline: 18195192]

13. Inouye SK, Westendorp RG, Saczynski JS. Delirium in elderly people. The Lancet 2014 Mar;383(9920):911-922. [doi: 10.1016/s0140-6736(13)60688-1]

14. Inouye SK, Bogardus ST, Charpentier PA, Leo-Summers L, Acampora D, Holford TR, et al. A Multicomponent Intervention to Prevent Delirium in Hospitalized Older Patients. N Engl J Med 1999 Mar 04;340(9):669-676. [doi: 10.1056/nejm199903043400901]

15. Devlin J, Skrobik Y, Gélinas C, Needham D, Slooter A, Pandharipande P, et al. Clinical Practice Guidelines for the Prevention and Management of Pain, Agitation/Sedation, Delirium, Immobility, and Sleep Disruption in Adult Patients in the ICU. Crit Care Med 2018 Sep;46(9):e825-e873. [doi: 10.1097/CCM.0000000000003299] [Medline: 30113379]

16. Marra A, Ely EW, Pandharipande PP, Patel MB. The ABCDEF Bundle in Critical Care. Crit Care Clin 2017 Apr;33(2):225-243 [FREE Full text] [doi: 10.1016/j.ccc.2016.12.005] [Medline: 28284292]

17. DAS-Taskforce 2015, Baron R, Binder A, Biniek R, Braune S, Buerkle H, et al. Evidence and consensus based guideline for the management of delirium, analgesia, and sedation in intensive care medicine. Revision 2015 (DAS-Guideline 2015) - short version. Ger Med Sci 2015;13:Doc19 [FREE Full text] [doi: 10.3205/000223] [Medline: 26609286]

18. Trogrlić Z, van der Jagt M, Bakker J, Balas MC, Ely EW, van der Voort PHJ, et al. A systematic review of implementation strategies for assessment, prevention, and management of ICU delirium and their effect on clinical outcomes. Crit Care 2015 Apr 09;19:157 [FREE Full text] [doi: 10.1186/s13054-015-0886-9] [Medline: 25888230]

19. van de Pol I, van Iterson M, Maaskant J. Effect of nocturnal sound reduction on the incidence of delirium in intensive care unit patients: An interrupted time series analysis. Intensive Crit Care Nurs 2017 Aug;41:18-25. [doi: 10.1016/j.iccn.2017.01.008] [Medline: 28351551]

20. Luetz A, Grunow JJ, Mörgeli R, Rosenthal M, Weber-Carstens S, Weiss B, et al. Innovative ICU Solutions to Prevent and Reduce Delirium and Post-Intensive Care Unit Syndrome. Semin Respir Crit Care Med 2019 Oct;40(5):673-686. [doi: 10.1055/s-0039-1698404] [Medline: 31826268]

21. Bott N, Wexler S, Drury L, Pollak C, Wang V, Scher K, et al. A Protocol-Driven, Bedside Digital Conversational Agent to Support Nurse Teams and Mitigate Risks of Hospitalization in Older Adults: Case Control Pre-Post Study. J Med Internet Res 2019 Oct 17;21(10):e13440. [doi: 10.2196/13440] [Medline: 31625949]

22. Kang J, Lee M, Ko H, Kim S, Yun S, Jeong Y, et al. Effect of nonpharmacological interventions for the prevention of delirium in the intensive care unit: A systematic review and meta-analysis. J Crit Care 2018 Dec;48:372-384. [doi: 10.1016/j.jcrc.2018.09.032] [Medline: 30300863]

23. Rivosecchi RM, Smithburger PL, Svec S, Campbell S, Kane-Gill SL. Nonpharmacological interventions to prevent delirium: an evidence-based systematic review. Crit Care Nurse 2015 Feb;35(1):39-50. [doi: 10.4037/ccn2015423] [Medline: 25639576]

24. Rivosecchi RM, Kane-Gill SL, Svec S, Campbell S, Smithburger PL. The implementation of a nonpharmacologic protocol to prevent intensive care delirium. J Crit Care 2016 Feb;31(1):206-211. [doi: 10.1016/j.jcrc.2015.09.031] [Medline: 26596509]

25. Bannon L, McGaughey J, Verghis R, Clarke M, McAuley DF, Blackwood B. The effectiveness of non-pharmacological interventions in reducing the incidence and duration of delirium in critically ill patients: a systematic review and meta-analysis. Intensive Care Med 2019 Jan;45(1):1-12. [doi: 10.1007/s00134-018-5452-x] [Medline: 30506354]

26. Martinez F, Tobar C, Hill N. Preventing delirium: should non-pharmacological, multicomponent interventions be used? A systematic review and meta-analysis of the literature. Age Ageing 2015 Mar;44(2):196-204. [doi: 10.1093/ageing/afu173] [Medline: 25424450]

27. Reston JT, Schoelles KM. In-facility delirium prevention programs as a patient safety strategy: a systematic review. Ann Intern Med 2013 Mar 05;158(5 Pt 2):375-380 [FREE Full text] [doi: 10.7326/0003-4819-158-5-201303051-00003] [Medline: 23460093]

28. Abraha I, Trotta F, Rimland JM, Cruz-Jentoft A, Lozano-Montoya I, Soiza RL, et al. Efficacy of Non-Pharmacological Interventions to Prevent and Treat Delirium in Older Patients: A Systematic Overview. The SENATOR project ONTOP Series. PLoS One 2015;10(6):e0123090 [FREE Full text] [doi: 10.1371/journal.pone.0123090] [Medline: 26062023]

29. Tricco AC, Lillie E, Zarin W, O'Brien KK, Colquhoun H, Levac D, et al. PRISMA Extension for Scoping Reviews (PRISMA-ScR): Checklist and Explanation. Ann Intern Med 2018 Oct 02;169(7):467-473 [FREE Full text] [doi: 10.7326/M18-0850] [Medline: 30178033]

30. Leentjens AF, Schieveld JN, Leonard M, Lousberg R, Verhey FR, Meagher DJ. A comparison of the phenomenology of pediatric, adult, and geriatric delirium. J Psychosom Res 2008 Feb;64(2):219-223. [doi: 10.1016/j.jpsychores.2007.11.003] [Medline: 18222136$]$

31. Holly C, Porter S, Echevarria M, Dreker M, Ruzehaji S. CE: Original Research: Recognizing Delirium in Hospitalized Children: A Systematic Review of the Evidence on Risk Factors and Characteristics. Am J Nurs 2018 Apr;118(4):24-36. [doi: 10.1097/01.NAJ.0000532069.55339.f9] [Medline: 29543606] 
32. Pandharipande P, Cotton BA, Shintani A, Thompson J, Costabile S, Truman Pun B, et al. Motoric subtypes of delirium in mechanically ventilated surgical and trauma intensive care unit patients. Intensive Care Med 2007 Aug 18;33(10):1860-1860. [doi: $10.1007 / \mathrm{s} 00134-007-0846-1]$

33. Byun S, Song S, Kim J, Ryu T, Jeong M, Kim E. Mother's recorded voice on emergence can decrease postoperative emergence delirium from general anaesthesia in paediatric patients: a prospective randomised controlled trial. Br J Anaesth 2018 Aug;121(2):483-489 [FREE Full text] [doi: 10.1016/j.bja.2018.01.042] [Medline: 30032889]

34. Kim H, Jung SM, Yu H, Park S. Video Distraction and Parental Presence for the Management of Preoperative Anxiety and Postoperative Behavioral Disturbance in Children. Anesthesia \& Analgesia 2015;121(3):778-784. [doi: 10.1213/ane.0000000000000839]

35. Rodriguez ST, Jang O, Hernandez JM, George AJ, Caruso TJ, Simons LE. Varying screen size for passive video distraction during induction of anesthesia in low-risk children: A pilot randomized controlled trial. Paediatr Anaesth 2019 Jun;29(6):648-655. [doi: 10.1111/pan.13636] [Medline: 30916447]

36. Dwairej DA, Obeidat HM, Aloweidi AS. Video game distraction and anesthesia mask practice reduces children's preoperative anxiety: A randomized clinical trial. J Spec Pediatr Nurs 2020 Jan;25(1):e12272. [doi: 10.1111/jspn.12272] [Medline: 31576651]

37. Eijlers R, Dierckx B, Staals LM, Berghmans JM, van der Schroeff MP, Strabbing EM, et al. Virtual reality exposure before elective day care surgery to reduce anxiety and pain in children: A randomised controlled trial. Eur J Anaesthesiol 2019 Oct;36(10):728-737 [FREE Full text] [doi: 10.1097/EJA.0000000000001059] [Medline: 31356373]

38. Ryu J, Oh A, Yoo H, Kim J, Park J, Han S. The effect of an immersive virtual reality tour of the operating theater on emergence delirium in children undergoing general anesthesia: A randomized controlled trial. Paediatr Anaesth 2019 Jan;29(1):98-105. [doi: 10.1111/pan.13535] [Medline: 30365231]

39. Lee C, Lee C, Hsu M, Lai C, Sung Y, Lin C, et al. Effects of Music Intervention on State Anxiety and Physiological Indices in Patients Undergoing Mechanical Ventilation in the Intensive Care Unit. Biol Res Nurs 2017 Mar;19(2):137-144. [doi: 10.1177/1099800416669601] [Medline: 27655993]

40. Damshens MH, Sanie MS, Javadpour S, Khaef MA, Rastgarian A. The Role of Music on the Delirium in Traumatic Patients: A Case Study in the ICU of Peymanieh Hospital of Jahrom, Fars Province, Iran. Ambient Science 2018 Jul;5(Sp1):97-101. [doi: 10.21276/ambi.2018.05.sp1.ra11]

41. Simons KS, Laheij RJF, van den Boogaard M, Moviat MAM, Paling AJ, Polderman FN, et al. Dynamic light application therapy to reduce the incidence and duration of delirium in intensive-care patients: a randomised controlled trial. The Lancet Respiratory Medicine 2016 Mar;4(3):194-202. [doi: 10.1016/s2213-2600(16)00025-4]

42. Potharajaroen S, Tangwongchai S, Tayjasanant T, Thawitsri T, Anderson G, Maes M. Bright light and oxygen therapies decrease delirium risk in critically ill surgical patients by targeting sleep and acid-base disturbances. Psychiatry Res 2018 Mar;261:21-27. [doi: 10.1016/j.psychres.2017.12.046] [Medline: 29276990]

43. Waszynski CM, Milner KA, Staff I, Molony SL. Using simulated family presence to decrease agitation in older hospitalized delirious patients: A randomized controlled trial. Int J Nurs Stud 2018 Jan;77:154-161. [doi: 10.1016/j.ijnurstu.2017.09.018] [Medline: 29100197]

44. Demoule A, Carreira S, Lavault S, Pallanca O, Morawiec E, Mayaux J, et al. Impact of earplugs and eye mask on sleep in critically ill patients: a prospective randomized study. Crit Care 2017 Nov 21;21(1):284 [FREE Full text] [doi: 10.1186/s13054-017-1865-0] [Medline: 29157258]

45. Giraud K, Pontin M, Sharples LD, Fletcher P, Dalgleish T, Eden A, et al. Use of a Structured Mirrors Intervention Does Not Reduce Delirium Incidence But May Improve Factual Memory Encoding in Cardiac Surgical ICU Patients Aged Over 70 Years: A Pilot Time-Cluster Randomized Controlled Trial. Front Aging Neurosci 2016;8:228 [FREE Full text] [doi: 10.3389/fnagi.2016.00228] [Medline: 27733826]

46. Lin Y, Shen W, Liu Y, Wang Q, Chen Q, Fang Z, et al. Visual preconditioning reduces emergence delirium in children undergoing ophthalmic surgery: a randomised controlled trial. Br J Anaesth 2018 Aug;121(2):476-482 [FREE Full text] [doi: 10.1016/j.bja.2018.03.033] [Medline: 30032888]

47. Mitchell ML, Kean S, Rattray JE, Hull AM, Davis C, Murfield JE, et al. A family intervention to reduce delirium in hospitalised ICU patients: A feasibility randomised controlled trial. Intensive Crit Care Nurs 2017 Jun;40:77-84. [doi: 10.1016/j.iccn.2017.01.001] [Medline: 28254205]

48. Johnson K, Fleury J, McClain D. Music intervention to prevent delirium among older patients admitted to a trauma intensive care unit and a trauma orthopaedic unit. Intensive Crit Care Nurs 2018 Aug;47:7-14. [doi: 10.1016/j.iccn.2018.03.007] [Medline: 29735284]

49. Munro CL, Cairns P, Ji M, Calero K, Anderson WM, Liang Z. Delirium prevention in critically ill adults through an automated reorientation intervention - A pilot randomized controlled trial. Heart Lung 2017;46(4):234-238. [doi: 10.1016/j.hrtlng.2017.05.002] [Medline: 28606450]

50. Lee WJ, Lee MJ. The Effects of Video Information on Delirium, Anxiety, and Nursing Satisfaction of Heart Surgery Patients. IJBSBT 2017 Dec 31;8(6):175-184. [doi: 10.14257/ijbsbt.2016.8.6.17] 
51. Arbabi M, Zebardast J, Noorbala AA, Mohamadi M, Rahimnia M, Larijani R. Efficacy of Liaison Education and Environmental Changes on Delirium Incidence in ICU. Arch Neurosci 2018 Apr 20;5(2):e56019. [doi: 10.5812/archneurosci.56019]

52. Gómez Tovar LO, Díaz Suárez L, Cortés Muñoz F. Cuidados de enfermería basados en evidencia y modelo de Betty Neuman, para controlar estresores del entorno que pueden ocasionar delirium en unidad de cuidados intensivos. eglobal 2016 Jan 09;15(1):49. [doi: 10.6018/eglobal.15.1.210841]

53. Sharda N, Mattoon E, Matters L, Prewitt J, McDonald S, Sloane R, et al. Bach to the Basics: Implementation and Impact of a Postoperative, Inpatient Personalized Music Program for Older Adults. J Perianesth Nurs 2019 Apr;34(2):347-353. [doi: 10.1016/j.jopan.2018.05.006] [Medline: $\underline{\text { 30205935] }}$

54. Smonig R, Magalhaes E, Bouadma L, Andremont O, de Montmollin E, Essardy F, et al. Impact of natural light exposure on delirium burden in adult patients receiving invasive mechanical ventilation in the ICU: a prospective study. Ann Intensive Care 2019 Oct 17;9(1):120 [FREE Full text] [doi: 10.1186/s13613-019-0592-x] [Medline: $\underline{31624936}$ ]

55. Cheong CY, Tan JAQ, Foong Y, Koh HM, Chen DZY, Tan JJC, et al. Creative Music Therapy in an Acute Care Setting for Older Patients with Delirium and Dementia. Dement Geriatr Cogn Dis Extra 2016;6(2):268-275 [FREE Full text] [doi: 10.1159/000445883] [Medline: 27489560]

56. Garry J, Casey K, Cole TK, Regensburg A, McElroy C, Schneider E, et al. A pilot study of eye-tracking devices in intensive care. Surgery 2016 Mar;159(3):938-944. [doi: 10.1016/j.surg.2015.08.012] [Medline: 26361099]

57. Suvajdzic M, Bihorac A, Rashidi P, Ruppert M, Williams S, Ozrazgat-Baslanti T. Developing a Patient-Centered Virtual Reality Healthcare System To Prevent the Onset of Delirium in ICU Patients. 2019 Presented at: 2019 IEEE 7th International Conference on Serious Games and Applications for Health (SeGAH); 5-7 August; Kyoto, Japan. [doi: 10.1109/SeGAH.2019.8882442]

58. Estrup S, Kjer CKW, Poulsen LM, Gøgenur I, Mathiesen O. Delirium and effect of circadian light in the intensive care unit: a retrospective cohort study. Acta Anaesthesiol Scand 2018 Mar;62(3):367-375. [doi: 10.1111/aas.13037] [Medline: 29148046]

59. Zachary W, Kirupananthan A, Cotter S, Barbara GH, Cooke RC, Sipho M. The impact of Hospital Elder Life Program interventions, on 30-day readmission Rates of older hospitalized patients. Arch Gerontol Geriatr 2020;86:103963. [doi: 10.1016/j.archger.2019.103963] [Medline: 31733512]

60. Pustjens T, Schoutens A, Janssen L, Heesen W. Effect of dynamic light at the coronary care unit on the length of hospital stay and development of delirium: a retrospective cohort study. J Geriatr Cardiol 2018 Sep 28;15(9):567-573 [FREE Full text] [doi: 10.11909/j.issn.1671-5411.2018.09.006] [Medline: $\underline{\text { 30344540] }}$

61. Ost LG. Applied relaxation: description of a coping technique and review of controlled studies. Behav Res Ther 1987;25(5):397-409. [doi: 10.1016/0005-7967(87)90017-9] [Medline: 3318800]

62. Hassenzahl M, Diefenbach S, Göritz A. Needs, affect, and interactive products - Facets of user experience. Interacting with Computers 2010 Sep;22(5):353-362. [doi: 10.1016/j.intcom.2010.04.002]

63. Russell JA, Mehrabian A. Evidence for a three-factor theory of emotions. Journal of Research in Personality 1977 Sep;11(3):273-294. [doi: 10.1016/0092-6566(77)90037-x]

64. Hu R, Hegadoren KM, Wang X, Jiang X. An investigation of light and sound levels on intensive care units in China. Aust Crit Care 2016 May;29(2):62-67. [doi: 10.1016/j.aucc.2015.08.001] [Medline: 26307553]

65. Leach J. Psychological factors in exceptional, extreme and torturous environments. Extrem Physiol Med 2016;5:7 [FREE Full text] [doi: 10.1186/s13728-016-0048-y] [Medline: 27257476]

66. Kordts B, Kopetz J, Henkel A, Scherader A, Jochems N. Requirements and interaction patters for a novel interaction device for patients in intensive care. i-com 2019;18(1):2019. [doi: 10.1515/icom-2019-0004]

67. Schulman-Marcus J, Mookherjee S, Rice L, Lyubarova R. New Approaches for the Treatment of Delirium: A Case for Robotic Pets. Am J Med 2019 Jul;132(7):781-782. [doi: 10.1016/j.amjmed.2018.12.039] [Medline: 30738728]

68. Özcan E, Birdja D, Simonse L, Struijs A. Alarm in the ICU! envisioning patient monitoring alarm management in future intensive care units. In: Pfannstiel M, Rasche C, editors. Service Design and Service Thinking in Healthcare and Hospital Management. Cham: Springer; 2019:421-446.

69. Lee C, Lai C, Sung Y, Lai MY, Lin C, Lin L. Comparing effects between music intervention and aromatherapy on anxiety of patients undergoing mechanical ventilation in the intensive care unit: a randomized controlled trial. Qual Life Res 2017 Jul;26(7):1819-1829. [doi: 10.1007/s11136-017-1525-5] [Medline: 28236262]

70. Gerber SM, Jeitziner M, Sänger SD, Knobel SEJ, Marchal-Crespo L, Müri RM, et al. Comparing the Relaxing Effects of Different Virtual Reality Environments in the Intensive Care Unit: Observational Study. JMIR Perioper Med 2019 Nov 15;2(2):e15579 [FREE Full text] [doi: 10.2196/15579] [Medline: 33393906]

71. Ludden GD, van Rompay TJ, Niedderer K, Tournier I. Environmental design for dementia care - towards more meaningful experiences through design. Maturitas 2019 Oct;128:10-16. [doi: 10.1016/j.maturitas.2019.06.011] [Medline: 31561816]

72. Greene SM, Tuzzio L, Cherkin D. A framework for making patient-centered care front and center. Perm J 2012;16(3):49-53 [FREE Full text] [Medline: 23012599]

73. Sharon T. Self-Tracking for Health and the Quantified Self: Re-Articulating Autonomy, Solidarity, and Authenticity in an Age of Personalized Healthcare. Philos. Technol 2016 Apr 18;30(1):93-121. [doi: 10.1007/s13347-016-0215-5] 
74. Mead N, Bower P. Patient-centredness: a conceptual framework and review of the empirical literature. Soc Sci Med 2000 Oct;51(7):1087-1110. [doi: 10.1016/s0277-9536(00)00098-8] [Medline: 11005395]

75. Davoudi A, Malhotra KR, Shickel B, Siegel S, Williams S, Ruppert M, et al. Intelligent ICU for Autonomous Patient Monitoring Using Pervasive Sensing and Deep Learning. Sci Rep 2019 May 29;9(1):8020 [FREE Full text] [doi: 10.1038/s41598-019-44004-w] [Medline: $\underline{31142754]}$

\section{Abbreviations}

ICU: intensive care unit

VR: virtual reality

Edited by $R$ Kukafka; submitted 27.11.20; peer-reviewed by MC Reade, YL Leung; comments to author 26.12.20; revised version received 12.02.21; accepted 24.05.21; published 26.08 .21

Please cite as:

Kim CM, van der Heide EM, van Rompay TJL, Verkerke GJ, Ludden GDS

Overview and Strategy Analysis of Technology-Based Nonpharmacological Interventions for In-Hospital Delirium Prevention and Reduction: Systematic Scoping Review

J Med Internet Res 2021;23(8):e26079

URL: https://www.jmir.org/2021/8/e26079

doi: $10.2196 / 26079$

PMID:

(C) Chan Mi Kim, Esther M van der Heide, Thomas J L van Rompay, Gijsbertus J Verkerke, Geke D S Ludden. Originally published in the Journal of Medical Internet Research (https://www.jmir.org), 26.08.2021. This is an open-access article distributed under the terms of the Creative Commons Attribution License (https://creativecommons.org/licenses/by/4.0/), which permits unrestricted use, distribution, and reproduction in any medium, provided the original work, first published in the Journal of Medical Internet Research, is properly cited. The complete bibliographic information, a link to the original publication on https://www.jmir.org/, as well as this copyright and license information must be included. 